Provided for non-commercial research and education use. Not for reproduction, distribution or commercial use.

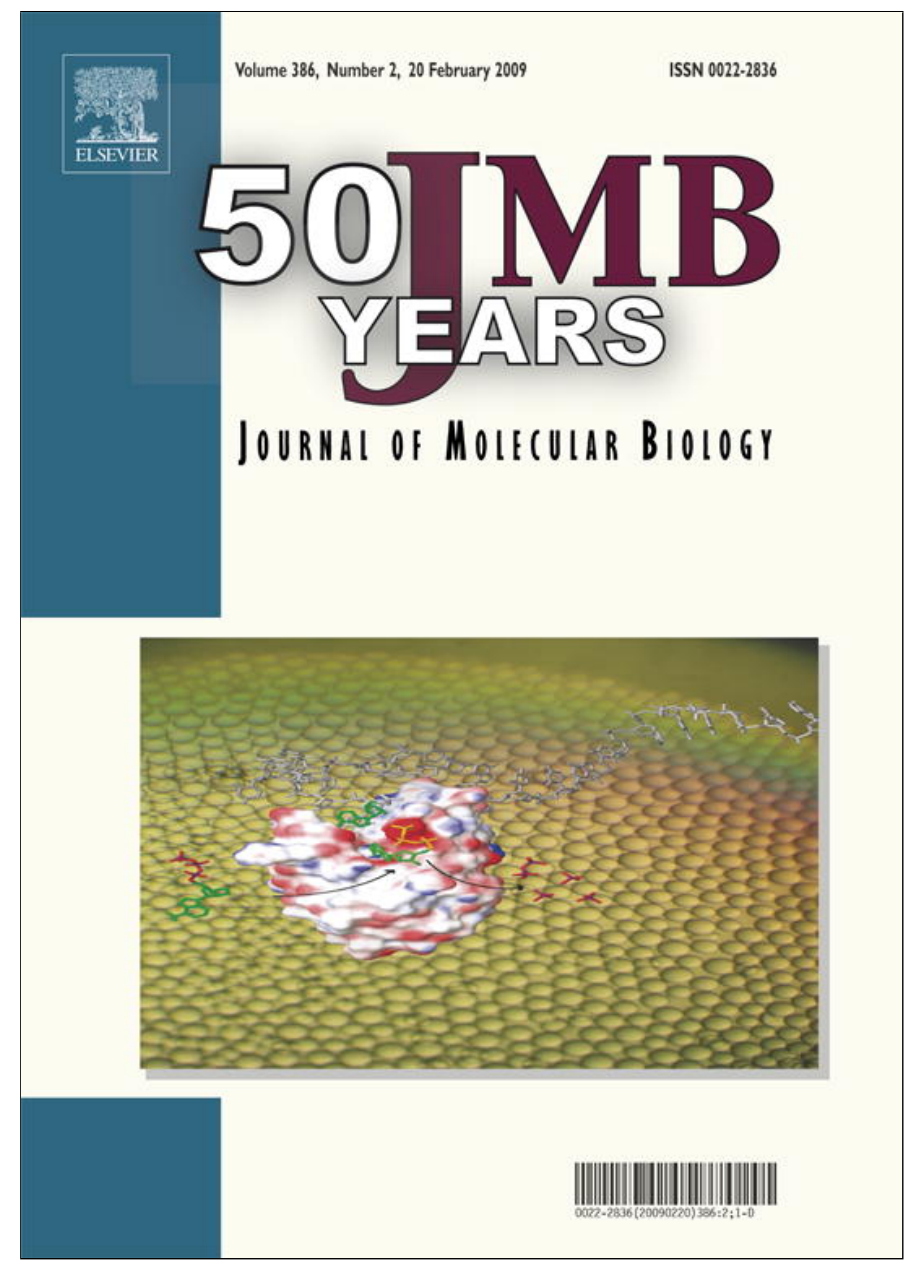

This article appeared in a journal published by Elsevier. The attached copy is furnished to the author for internal non-commercial research and education use, including for instruction at the authors institution and sharing with colleagues.

Other uses, including reproduction and distribution, or selling or licensing copies, or posting to personal, institutional or third party websites are prohibited.

In most cases authors are permitted to post their version of the article (e.g. in Word or Tex form) to their personal website or institutional repository. Authors requiring further information regarding Elsevier's archiving and manuscript policies are encouraged to visit:

http://www.elsevier.com/copyright 


\title{
The Collagen Binding Domain of Gelatinase A Modulates Degradation of Collagen IV by Gelatinase B
}

\author{
Magda Gioia ${ }^{1,2,3} \dagger$, Susanna Monaco ${ }^{1,4} \dagger$, Philippe E. Van Den Steen ${ }^{5}$, \\ Diego Sbardella ${ }^{1}$, Giuseppe Grasso ${ }^{6,7}$, Stefano Marini ${ }^{1,4}$, \\ Christopher M. Overall ${ }^{2,3}$, Ghislain Opdenakker ${ }^{5}$ \\ and Massimo Coletta ${ }^{1,4 *}$
}

\author{
${ }^{1}$ Department of Experimental \\ Medicine and Biochemical \\ Sciences, University of Roma \\ Tor Vergata, Via Montpellier 1, \\ I-00133 Rome, Italy \\ ${ }^{2}$ Department of Oral Biological \\ and Medical Sciences, \\ Biochemistry and Molecular \\ Biology, University of British \\ Columbia, Vancouver, BC, \\ Canada V6T1Z3 \\ ${ }^{3}$ Department of Biochemistry \\ and Molecular Biology, \\ University of British Columbia, \\ Vancouver, BC, Canada \\ V6T1Z3 \\ ${ }^{4}$ Interuniversity Consortium for \\ the Research on the Chemistry of \\ Metals in Biological Systems, \\ P.za Umberto I 1, I-70100 Bari, \\ Italy \\ ${ }^{5}$ Rega Institute for Medical \\ Research, Laboratory of \\ Immunobiology, University of \\ Leuven, Minderbroedersstraat \\ 10, B-3000 Leuven, Belgium \\ ${ }^{6}$ Department of Chemistry, \\ University of Catania, \\ V.le A. Doria, Catania, Italy \\ ${ }^{7}$ Institute of Biostructure and \\ Bioimaging, CNR, \\ V.le A. Doria, Catania, Italy
}

\begin{abstract}
Type IV collagen remodeling plays a critical role in inflammatory responses, angiogenesis and metastasis. Its remodeling is executed by a family of matrix metalloproteinases (MMPs), of which the constitutive gelatinase A (MMP2) and the inducible gelatinase B (MMP9) are key examples. Thus, in many pathological conditions, both gelatinases act together. Kinetic data are reported for the enzymatic processing at $37^{\circ} \mathrm{C}$ of type IV collagen from human placenta by MMP9 and its modulation by the fibronectin-like collagen binding domain (CBD) of MMP2. The $\alpha 1$ and $\alpha 2$ chain components of type IV collagen were cleaved by gelatinases and identified by mass spectrometry as well as Edman sequencing. Surface plasmon resonance interaction assays showed that CBD bound type IV collagen at two topologically distinct sites. On the basis of linked-function analysis, we demonstrated that CBD of MMP2 tuned the cleavage of collagen IV by MMP9, presumably by inducing a ligand-linked structural change on the type IV collagen. At low concentrations, the CBD bound the first site and thereby allosterically modulated the binding of MMP9 to collagen IV, thus enhancing the collagenolytic activity of MMP9. At high concentrations, CBD binding to the second site interfered with MMP9 binding to collagen IV, acting as a competitive inhibitor. Interestingly, modulation of collagen IV degradation by inactive forms of MMP2 also occurred in a cell-based system, revealing that this interrelationship affected neutrophil migration across a collagen IV membrane. The regulation of the proteolytic processing by a catalytically inactive domain (i.e., CBD) suggests that the two gelatinases might cooperate in degrading substrates even when either one is inactive. This observation reinforces the idea of exosite targets for MMP inhibitors, which should include all macromolecular substrate recognition sites.
\end{abstract}

(C) 2008 Elsevier Ltd. All rights reserved.

*Corresponding author. E-mail address: coletta@seneca.uniroma2.it.

$\dagger$ M. Gioia and S. Monaco equally contributed to this work.

Abbreviations used: MMP, matrix metalloproteinase; MMP2, gelatinase A; MMP9, gelatinase B; CBD, collagen binding domain; MCA, (7-methoxycoumarin-4-yl)acetyl; DPA, N-3-(2,4-dinitrophenyl)-L-2,3-diaminopropionyl; PDMS, poly(dimethylsiloxane); DMSO, dimethyl sulfoxide; SPR, surface plasmon resonance; SPRI, surface plasmon resonance imaging; NC1 domain, noncollagenous domain; MS, mass spectrometry; EHS, Engelbreth-Holm-Swarm; LPS, lipopolysaccharide; OPD, orthophenylendiamine. 
Received 16 September 2008;

received in revised form

4 December 2008;

accepted 5 December 2008

Available online

14 December 2008

Edited by M. Moody

Keywords: matrix metalloproteinases; gelatinase B; collagen binding domain; type IV collagen fragmentation; kinetics

\section{Introduction}

Matrix metalloproteinases (MMPs) are a class of endopeptidases characterized by a $\mathrm{Zn}^{2+}$ ion in the active site that is coordinated by three histidyl residues. MMPs are collectively capable of clearing most of the extracellular molecules, playing important roles in normal tissue homeostasis. ${ }^{1}$ The domain structure is remarkably similar among MMPs, showing a propeptide domain, which is removed upon enzyme activation, a catalytic domain and a hemopexin-like domain, which are connected by a hinge region. ${ }^{2}$ Moreover, gelatinases $\mathrm{A}$ and B (MMP2 and MMP9) possess a unique collagen binding domain (CBD), also called fibronectin-like domain and consisting of three 58-aa fibronectin type II-like modules, ${ }^{3}$ that is inserted between the active site and the $\mathrm{Zn}^{2+}$ binding domain. Furthermore, only in the case of MMP9 is the hinge region a long O-glycosylated domain. ${ }^{4}$

Although most MMPs have similar substrate specificities, their redundant activities are kept separated by tissue distribution and regulation. ${ }^{5}$ In particular, gelatinases (i.e., MMP2 and MMP9) are normally compartmentalized, with MMP2 being present in blood serum at high concentrations (up to $160 \mathrm{ng} / \mathrm{ml})^{6}$ and MMP9 being mostly stored in neutrophil granules. Moreover, unlike the constitutive MMP2, the expression and secretion of MMP9 are highly regulated..$^{7-10}$ Gene knockout studies have suggested that the gelatinases may cooperate in vivo. ${ }^{11-13}$ In this respect, an example may be represented by the process of inflammation, wherein the degranulation of extravasated neutrophils allows MMP2 and MMP9 to share the same extracellular space, thus enhancing the probability to interact with the same substrates. ${ }^{14}$ Neutrophil degranulation is associated with the ability of neutrophils to cross basement membranes, composed mainly of a type IV collagen network; ${ }^{15,16}$ therefore, the enzymatic activities of MMP2 and MMP9 on type IV collagen are likely relevant for this process.

Collagens are modular triple-helical proteins that display different self-organizing superstructures, such as fibrils and networks, that play functional roles in cell adhesion, cell differentiation and tissue development. ${ }^{17}$ Collagen IV molecules do not aggregate in a parallel fashion into fibers but are assembled via their end regions, forming a loose network of monomers, formed by three $\alpha$ chains that are held together by disulfide bonds. ${ }^{18}$ Although with six
$\alpha(\mathrm{IV})$ chains the triple-helical protomer gives rise to 56 possible combinations, it usually assembles into an $\alpha$-chain trimer composed of two $\alpha 1$ chains and one $\alpha 2$ chain. ${ }^{19-23}$ Collagen type IV possesses three domains: an amino-terminal 7S domain, a middle triple-helical domain and a carboxy-terminal globular noncollagenous (NC1) domain. The enzymatic fragmentation of collagen IV may produce the isolated NC1 domain, which is an active inhibitor of angiogenesis and cell migration. ${ }^{24-26}$

Collagenolytic activities and MMP inhibition have been largely studied on triple-helical synthetic substrates. ${ }^{27,28}$ Also, the role of the CBD exosite in modulating type I collagen degradation has been extensively documented. ${ }^{29-34}$ Nevertheless, despite the importance of type IV collagen degradation, it has been little studied. ${ }^{35}$ We have recently shown that MMP2 is able to cleave the $\alpha 1$ and $\alpha 2$ chains of type IV collagen at $37^{\circ} \mathrm{C}$ and that its CBD is involved in the recognition of both chains by MMP2. ${ }^{36}$ In this study, we analyzed the processing by human MMP9 of soluble human type IV collagen, whose $\alpha$-chain composition has been evaluated by mass spectrometry (MS) analysis. Furthermore, in view of the possible cooperation between MMP2 and MMP9 ${ }^{14}$ we investigated for the first time the synergy between the MMP2 CBD and MMP9 in collagen IV degradation in order to better understand the enzymatic processing of the basement membrane. In this regard, it is worth stressing that the reverse investigation (i.e., the synergy of MMP9 CBD and MMP2 in degrading native collagen IV) cannot be studied as the CBD of MMP9 has been reported to bind collagen IV only at high concentrations. ${ }^{31-36}$

The biological relevance of the reported modulation is validated by the accompanying observations on the effect of this interaction on neutrophil chemokinesis, raising important questions on the strategy for the design of efficient and selective inhibitors against macromolecular substrates.

\section{Results}

\section{Digestion of type IV collagen by gelatinases}

To study the kinetic degradation of type IV collagen, the major structural component of basement membrane, we used soluble forms of type IV collagen. Commonly, the two ways for rendering collagen IV soluble are (i) employing a gentle pepsin 
(a)

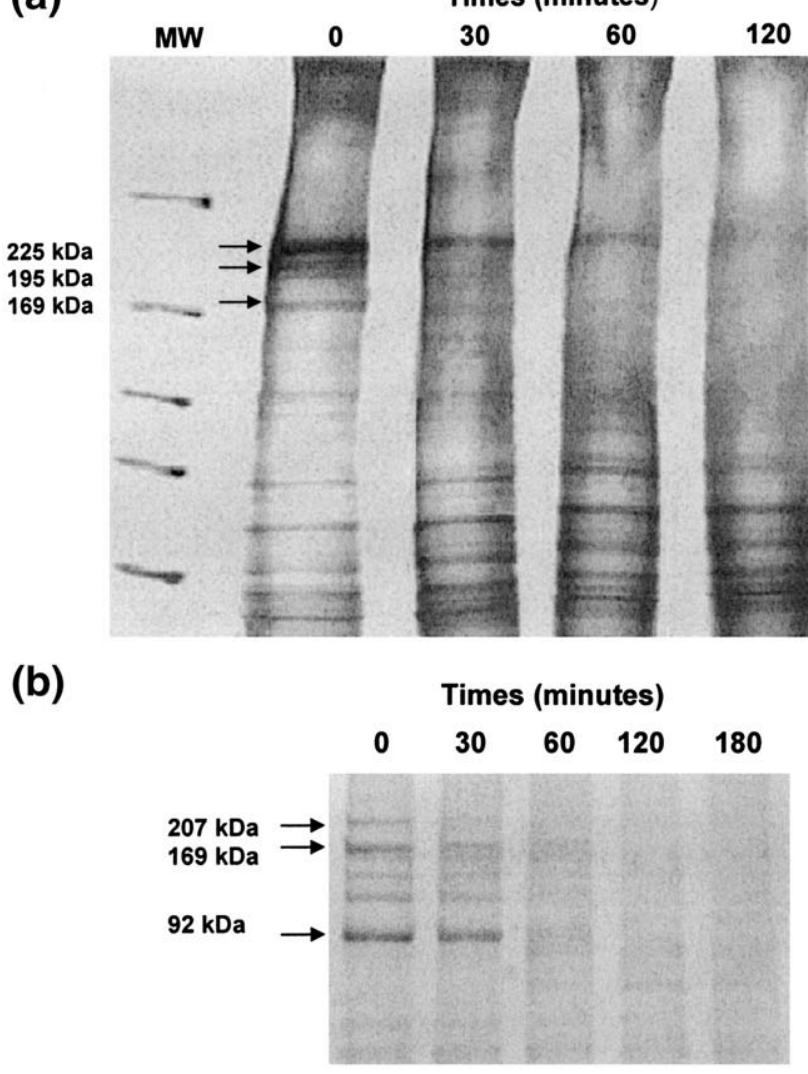

digestion of a tissue with high collagen IV content and (ii) generating in vitro soluble collagen IV by immortalized cells. Both forms of collagen IV [i.e., from human placenta and from murine EngelbrethHolm-Swarm (EHS) sarcoma] were digested by both gelatinases $^{36}$ (Fig. $1 \mathrm{a}$ and $\mathrm{b}$ ), showing behavior compatible with the Michaelis-Menten mechanism ${ }^{36}$ (Fig. 2a and b). In the case of unpepsinized collagen IV, three species (characterized by molecular masses of 225, 195 and $169 \mathrm{kDa}$ ) appear to be significantly cleaved by MMP9, while the other species with a lower molecular mass seem to be resistant to the cleavage event (Fig. 1a). The overall catalytic efficiency of MMP9 is not drastically different for these three species (as from $k_{\text {cat }} / K_{\mathrm{m}}$; Table 1 ). As shown in Fig. $1 b$, a gentle pepsin digestion of human placenta generated sharp electrophoretic bands, rendering feasible a thorough biochemical study of the degradation of collagen IV and allowing for the correct identification of the processed bands. In particular, the enzymatic processing was further investigated for the three bands of collagen IV, namely, those characterized by molecular masses of 207, 169 and $92 \mathrm{kDa}$.

\section{Identification of collagen IV chains by Edman sequencing and MS}

Type IV collagen exists in six isoforms [i.e., $\alpha 1$ (IV) $-\alpha 6(\mathrm{IV})]$. Here, we identified the sequences of collagen IV of the three electrophoretic bands (i.e., 207, 169 and $92 \mathrm{kDa}$ ) for which enzymatic fragmentation was followed (Fig. 1b).
Fig. 1. SDS-PAGE separation of MMP9-processed collagen type IV as a function of time at $37^{\circ} \mathrm{C}$. Type IV collagen extracted from murine EHS sarcoma (a) and that from human placenta (b) are shown. Species under investigation are indicated by arrows. For further details, see the text.

On the basis of sequence-based mass determination, ${ }^{37,38}$ the $92-\mathrm{kDa}$ band was purified and sequenced, resulting in the experimental amino
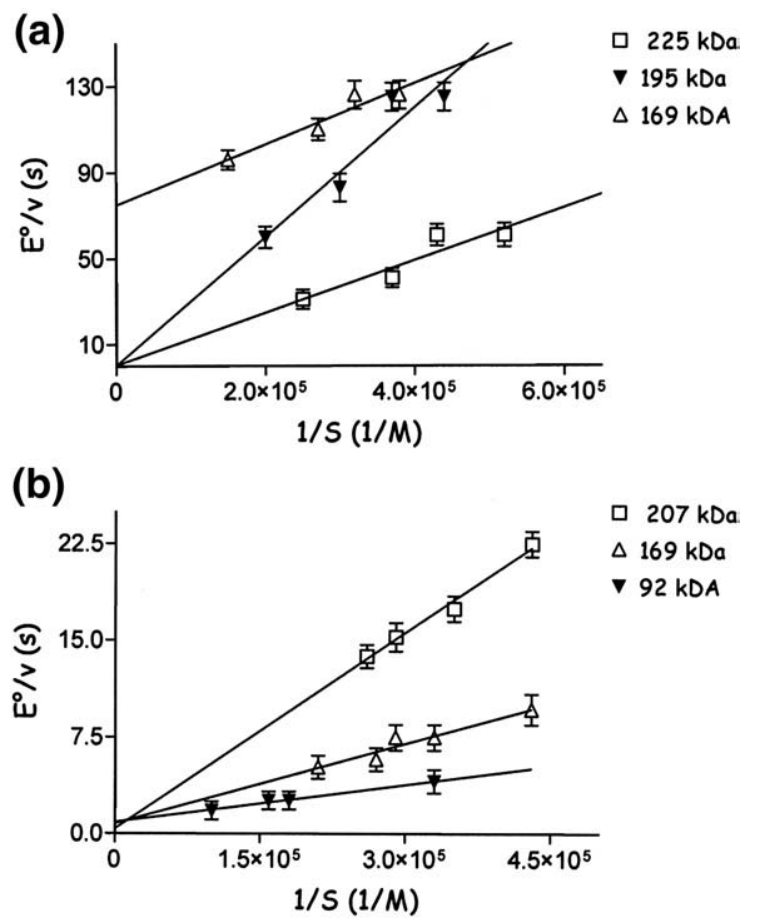

Fig. 2. Lineweaver-Burk plots of the processing by MMP9 of different species of collagen type IV from murine EHS sarcoma (a) and that from human placenta (b). Catalytic parameters are reported in Table 1. For further details, see the text. 
Table 1. Catalytic parameters for the enzymatic processing of collagen IV at $37^{\circ} \mathrm{C}$

\begin{tabular}{|c|c|c|c|}
\hline & $k_{\mathrm{cat}} / K_{\mathrm{m}}\left(\mathrm{M}^{-1} \mathrm{~s}^{-1}\right)$ & $k_{\text {cat }}\left(\mathrm{s}^{-1}\right)$ & $K_{\mathrm{m}}(\mathrm{M})$ \\
\hline \multicolumn{4}{|c|}{ Cleavage of unpepsinized collagen IV (EHS) by MMP9 } \\
\hline $225 \mathrm{kDa}$ & $8.1 \pm 1.0 \times 10^{3}$ & $3.4 \pm 0.3$ & $4.2 \pm 0.6 \times 10^{-4}$ \\
\hline $195 \mathrm{kDa}$ & $3.6 \pm 0.5 \times 10^{3}$ & $0.7 \pm 0.1$ & $1.9 \pm 0.3 \times 10^{-4}$ \\
\hline $169 \mathrm{kDa}$ & $6.1 \pm 0.8 \times 10^{3}$ & $1.4 \pm 0.2 \times 10^{-2}$ & $2.3 \pm 0.4 \times 10^{-6}$ \\
\hline \multicolumn{4}{|c|}{ Cleavage of native placental collagen IV by $\mathrm{M}$} \\
\hline $207 \mathrm{kDa}$ & $2.0 \pm 0.2 \times 10^{4}$ & $10.2 \pm 1.6$ & $5.2 \pm 0.6 \times 10^{-4}$ \\
\hline $169 \mathrm{kDa}$ & $4.9 \pm 0.5 \times 10^{4}$ & $1.4 \pm 0.2$ & $2.9 \pm 0.3 \times 10^{-5}$ \\
\hline $92 \mathrm{kDa}$ & $1.2 \pm 0.2 \times 10^{5}$ & $1.2 \pm 0.2$ & $1.0 \pm 0.1 \times 10^{-5}$ \\
\hline \multicolumn{4}{|c|}{ Cleavage of denatured placental collagen IV by MMP9 } \\
\hline $207 \mathrm{kDa}$ & $2.0 \pm 0.3 \times 10^{5}$ & $4.9 \pm 0.6$ & $2.4 \pm 0.4 \times 10^{-5}$ \\
\hline $169 \mathrm{kDa}$ & $1.4 \pm 0.3 \times 10^{5}$ & $7.8 \pm 1.0$ & $5.6 \pm 0.8 \times 10^{-5}$ \\
\hline \multicolumn{4}{|c|}{ Cleavage of native placental collagen IV by $\mathrm{MMP2}^{\mathrm{a}}$} \\
\hline $207 \mathrm{kDa}$ & $1.4 \pm 0.1 \times 10^{6}$ & $1.76 \pm 0.18$ & $1.2 \pm 0.13 \times 10^{-6}$ \\
\hline $169 \mathrm{kDa}$ & $1.1 \pm 0.1 \times 10^{6}$ & $2.97 \pm 0.3$ & $2.7 \pm 0.3 \times 10^{-6}$ \\
\hline 92 kDa & $1.1 \pm 0.1 \times 10^{5}$ & $17.00 \pm 0.16$ & $1.5 \pm 0.12 \times 10^{-4}$ \\
\hline
\end{tabular}

a Parameters reported for MMP2 have been previously published. $^{36}$ acid sequence (E)AIQPGXIAGP..., where " $X$ " is a cysteine that was undetectable by the Edman degradation analysis. This amino acid sequence corresponded to the $\alpha 2$ chain of human collagen IV, with amino-termini at positions 675 and 676 (occurring as a mixture), suggesting that this species is a fragment due to pepsin digestion. Hence, the $92-\mathrm{kDa}$ band was found to be an $\alpha 2$ fragment slightly bigger than half the whole chain and presumably included the NC1 domain ( $\mathrm{NC} 1$ is defined as the portion from residue 1555 to residue 1669 of the $\alpha 2$ chain) (Swiss-Prot Data Bank accession number P08572).

The 207- and 169-kDa electrophoretic bands were identified by peptide mass fingerprinting and tandem MS. Each single band was digested with trypsin, and the masses of the resulting peptides were measured with a tandem matrix-assisted laser desorption/ionization mass spectrometer. Protein identification was performed through automated database searching using MS-based peptide mass fingerprinting combined with MS/MS ion search. As shown in Table 1, the 207- and 169-kDa species were

Table 2. Collagen IV $\alpha 1$ chain 207- and 169-kDa bands

\begin{tabular}{|c|c|c|c|c|c|}
\hline \multicolumn{6}{|c|}{ collagen IV $\alpha 1$ chain } \\
\hline \multicolumn{6}{|c|}{$207 \mathrm{kDa}$ and $169 \mathrm{kDa}$ Bands } \\
\hline 1 & MGPRLSVWLL & LLPAALLLHE & EHSRAAAKGG & CAGSGCGKCD & CHGVKGQKGE \\
\hline 51 & RGLPGLQGVI & GFPGMQGPEG & PQGPPGQKGD & TGEPGLPGTK & GTRGPPGASG \\
\hline 101 & YPGNPGLPGI & PGQDGPPGPP & GIPGCNGTKG & ERGPLGPPGL & PGFAGNPGPP \\
\hline 151 & GLPGMKGDPG & EILGHVPGML & LKGERGFPGI & PGTPGPPGLP & GLQGPVGPPG \\
\hline 201 & FTGPPGPPGP & PGPPGEKGQM & GLSFQGPKGD & KGDQGVSGPP & GVPGQAQVQE \\
\hline 251 & KGDFATKGEK & GQKGEPGFQG & MPGVGEKGEP & GKPGPRGKPG & KDGDKGEKGS \\
\hline 301 & PGFPGEPGYP & GLIGRQGPQG & EKGEAGPPGP & PGIVIGTGPL & GEKGERGYPG \\
\hline 351 & $\underline{\text { TPGPRGEPGP }}$ & KGFPGLPGQP & GPPGLPVPGQ & AGAPGFPGER & GEKGDRGFPG \\
\hline 401 & $\overline{\text { TSLPGPSGRD }}$ & GLPGPPGSPG & PPGQPGYTNG & IVECQPGPPG & DQGPPGIPGQ \\
\hline 451 & PGFIGEIGEK & GQKGESCLIC & DIDGYRGPPG & PQGPPGEIGF & PGQPGAKGDR \\
\hline 501 & GLPGRDGVAG & VPGPQGTPGL & IGQPGAKGEP & GEFYFDLRLK & GDKGDPGFPG \\
\hline 551 & QPGMTGRAGS & PGRDGHPGLP & GPKGSPGSVG & LKGERGPPGG & VGFPGSRGDT \\
\hline 601 & GPPGPPGYGP & AGPIGDKGQA & GFPGGPGSPG & LPGPKGEPGK & IVPLPGPPGA \\
\hline 651 & EGLPGSPGFP & GPQGDRGFPG & TPGRPGLPGE & KGAVGQPGIG & FPGPPGPKGV \\
\hline 701 & DGLPGDMGPP & GTPGRPGFNG & LPGNPGVQGQ & KGEPGVGLPG & LKGLPGLPGI \\
\hline 751 & PGTPGEKGSI & GVPGVPGEHG & AIGPPGLQGI & RGEPGPPGLP & GSVGSPGVPG \\
\hline 801 & IGPPGARGPP & GGQGPPGLSG & PPGIKGEKGF & PGFPGLDMPG & PKGDKGAQGL \\
\hline 851 & $\overline{\text { PGITGQSGLP }}$ & GLPGQQGAPG & IPGFPGSKGE & MGVMGTPGQP & GSPGPVGAPG \\
\hline 901 & LPGEKGDHGF & PGSSGPRGDP & GLKGDKGDVG & LPGKPGSMDK & VDMGSMKGQK \\
\hline 951 & GDQGEKGQIG & PIGEKGSRGD & PGTPGVPGKD & GQAGQPGQPG & PKGDPGISGT \\
\hline 1001 & PGAPGLPGPK & GSVGGMGLPG & TPGEKGVPGI & PGPQGSPGLP & GDKGAKGEKG \\
\hline 1051 & QAGPPGIGIP & GLRGEKGDQG & IAGFPGSPGE & KGEKGSIGIP & GMPGSPGLKG \\
\hline 1101 & SPGSVGYPGS & PGLPGEKGDK & GLPGLDGIPG & VKGEAGLPGT & PGPTGPAGQK \\
\hline 1151 & GEPGSDGIPG & SAGEKGEPGL & PGRGFPGFPG & AKGDKGSKGE & VGFPGLAGSP \\
\hline 1201 & GI PGSKGEQG & FMGPPGPQGQ & PGLPGSPGHA & TEGPKGDRGP & QGQPGLPGLP \\
\hline 1251 & GPMGPPGLPG & IDGVKGDKGN & PGWPGAPGVP & GPKGDPGFQG & MPGIGGSPGI \\
\hline 1301 & TGSKGDMGPP & GVPGFQGPKG & LPGLQGI KGD & QGDQGVPGAK & GLPGPPGPPG \\
\hline 1351 & PYDI IKGEPG & LPGPEGPPGL & KGLQGLPGPK & GQQGVTGLVG & IPGPPGIPGF \\
\hline 1401 & DGAPGQKGEM & GPAGPTGPRG & FPGPPGPDGL & PGSMGPPGTP & SVDHGFLVTR \\
\hline 1451 & HSQTIDDPQC & PSGTKILYHG & YSLLYVQGNE & RAHGQDLGTA & GSCLRKFSTM \\
\hline 1501 & PFLFCNINNV & CNFASRNDYS & YWLSTPEPMP & MSMAPITGEN & IRPFISRCAV \\
\hline 1551 & CEAPAMVMAV & HSQTIQIPPC & PSGWSSLWIG & YSFVMHTSAG & AEGSGQALAS \\
\hline 1601 & PGSCLEEFRS & APFIECHGRG & TCNYYANAYS & FWLAT IERSE & MFKKPTPSTL \\
\hline 1651 & KEAGELRTHVS & RCQVCMRRT & & & \\
\hline
\end{tabular}

Collagen IV $\alpha 1$ chain identification of 207- and 169-kDa bands by complementary peptide mass fingerprinting and fragment mass fingerprinting. Underlined sequences are the identified tryptic peptides. The peptides reported in bold were found in both bands. The 7S domain (residues 28-172) and the NC1 domain (residues 1445-1669) are highlighted in yellow (Swiss-Prot Data Bank accession number P02462). 
successfully identified with high confidence as collagen IV $\alpha 1$ chains. Specifically, the $207-\mathrm{kDa}$ species was identified as the intact $\alpha 1$ chain (Table 2 ), whereas the 169-kDa form was assigned to a fragment of the $\alpha 1$ chain that lacks the 7S N-terminal domain (Table 2) (the 7S domain of $\alpha 1$ chain has been reported to be the portion between residues 28 and 172) (Swiss-Prot Data Bank accession number P02462).

\section{Kinetic parameters of MMP9 degradation of native and denatured collagen IV}

Although collagen IV was enzymatically processed in solution, data analysis was performed upon the $\alpha$ chain separation. Figure 1b shows the electrophoretic pattern, under reducing conditions, of the enzymatic processing of soluble collagen type IV from human placenta by MMP9 at $37^{\circ} \mathrm{C}$. Kinetic analysis was focused on the proteolytic cleavage of the three bands mentioned above. It is important to underline that the enzymatic processing of these three species was shown to follow the MichaelisMenten mechanism, as from the linearity of the reciprocal plot for the velocity versus substrate concentration (Fig. 2b). The catalytic parameters of the proteolytic cleavage were determined, and it was derived that the catalytic efficiency of MMP9 was the highest for the $\alpha 2$ chain (i.e., the $92-\mathrm{kDa}$ species) $\left(k_{\text {cat }} / K_{\mathrm{m}}\right.$ values; Table 1$)$. In addition, the ratelimiting step for the proteolytic cleavage (indicated by $k_{\text {cat }}$ values) turned out to be fastest for the intact $\alpha 1$ chain (i.e., the 207-kDa species). Furthermore, substrate affinity (referable to the $K_{\mathrm{m}}$ value; Table 1 ) was considerably lower for the intact $\alpha 1$ chain than for the $\alpha 1$ chain missing the 7S N-terminal domain (the highest affinity being observed for the $92-\mathrm{kDa}$ fragment of the $\alpha 2$ chain; Table 1).

Therefore, these data indicate that removal of the $7 S$ domain (in the 169-kDa species) induces a 20-fold increase for substrate affinity to MMP9 (as indicated by the decrease in $K_{\mathrm{m}}$; Table 1 ), accompanied by a 10 -fold decrease in $k_{\text {cat }}$. This suggests that the presence of the 7S domain heavily interferes with the main binding site of MMP9, decreasing its affinity for collagen IV.

A parallel investigation on the catalytic parameters for the 207- and 169-kDa species of native and denatured collagen type IV indicated that denaturation induced a marked increase in the catalytic efficiency by MMP9 (Table 1), which became similar to that observed for the 92-kDa species, which indeed has been proposed to be a fragmented (and partially denatured) form of the $\alpha 2$ chain. ${ }^{38,39}$

\section{CBD of MMP2 modulates MMP9 processing of type IV collagen}

The CBD is an exosite that drives the gelatinase positioning on substrates. ${ }^{30,40}$ The binding of the MMP2 CBD unwinds native collagen I, facilitating its cleavage. ${ }^{30,34}$ Here, we investigated the effect of MMP2 CBD on collagen IV degradation by MMP9. Figure 3 shows the processing of type IV collagen by

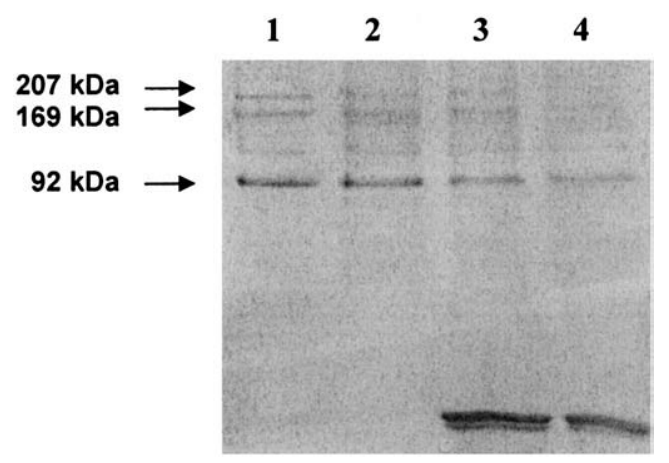

Fig. 3. SDS-PAGE of collagen type IV from human placenta after $30 \mathrm{~min}$ of exposure to MMP9 at $37^{\circ} \mathrm{C}$ in the absence of $20 \mu \mathrm{M}$ CBD (lane 2), in the presence of $20 \mu \mathrm{M}$ CBD (lane 3) and in the presence of $5 \mu \mathrm{M} \mathrm{CBD}$ (lane 4). Lane 1 reports collagen type IV from human placenta not exposed to MMP9. For further details, see the text.

MMP9 in the absence and in the presence of MMP2 CBD, which is known to bind collagen IV in the micromolar range. ${ }^{29}$ For the $207-\mathrm{kDa}$ band (the whole $\alpha 1$ chain), it was clear that, at $5 \mu \mathrm{M}, \mathrm{CBD}$ facilitates MMP9 activity (Fig. 3, lane 2 versus lane 4), while at higher concentrations (e.g., $20 \mu \mathrm{M}$ ), the effect seems to be reduced (Fig. 3, lane 3 versus lane 4). Since MMP2 CBD is enzymatically inactive, this observation suggested that (i) the binding site of MMP2 CBD is different from that of MMP9, underlying the possibility that the two gelatinases have distinct binding sites on collagen IV, and (ii) the two binding sites are functionally linked such that binding of MMP2 CBD affects the enzymatic action of MMP9 on the same substrate. To validate the specific effect of CBD, we performed analogous control experiments in the presence of PEG (polyethylene glycol) 1500. This crowding agent did not affect the collagenolytic activity (data not shown).

\section{Allosteric regulation of MMP2 CBD on the degradation of collagen IV by MMP9}

In order to understand how MMP2 CBD regulates collagen IV degradation by MMP9, we carried out a series of kinetic experiments as a function of the concentration of the MMP2 CBD. An extensive quantitative analysis allowed for the derivation of the kinetic parameters that characterize the CBDlinked effect on the binding of type IV collagen by MMP9 (i.e., $K_{\mathrm{m}}$ ) and MMP9 (i.e., $k_{\text {cat }} / K_{\mathrm{m}}$ ) enzymatic activities (Fig. 4). The dependence of catalytic parameters for the proteolytic processing by MMP9 on the concentration of MMP2 CBD was investigated for the three species (i.e., the 207, 169 and $92 \mathrm{kDa}$ ). At low concentrations (i.e., $<10 \mu \mathrm{M}$ ), CBD facilitated collagen IV hydrolysis by MMP9 (as from $k_{\text {cat }} / K_{\mathrm{m}}$ values; Fig. $\left.4 \mathrm{a}\right)$. On the other hand, a relevant decrease in MMP9 enzymatic efficiency was observed at higher concentrations of CBD (Fig. $4 a)$. Looking at the $K_{\mathrm{m}}$ values, it is clear that in both cases, the modulation is completely referable to a 
(a)

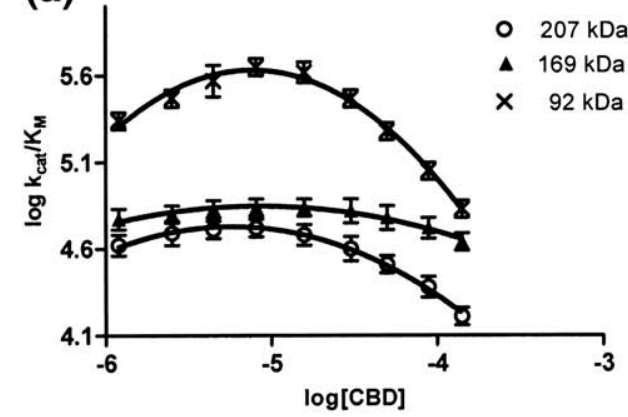

(b)

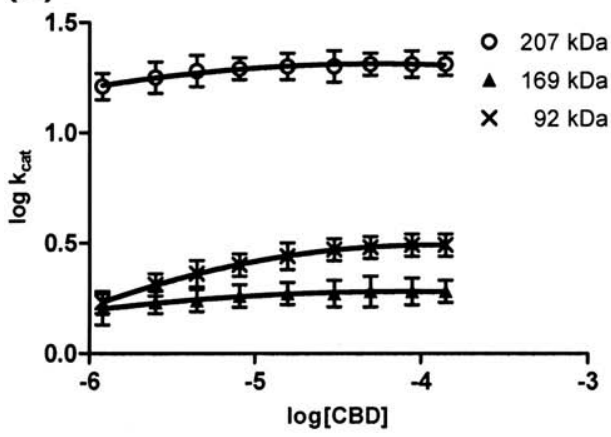

(c)

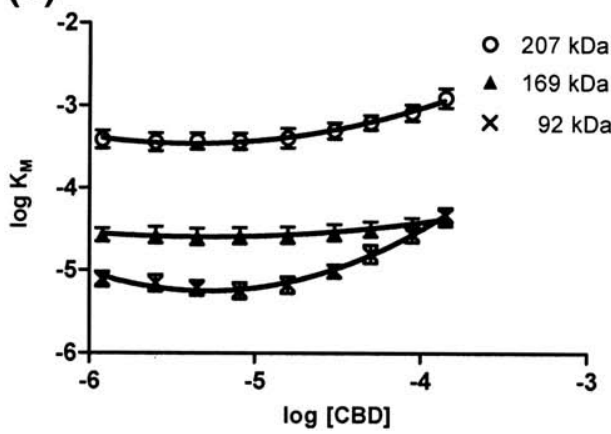

Fig. 4. Dependence on CBD concentration of enzymatic processing of collagen type IV from human placenta by MMP9 at $37^{\circ} \mathrm{C}$ and $\mathrm{pH} 7.1$ for $k_{\text {cat }} / K_{\mathrm{m}}(\mathrm{a}), K_{\mathrm{m}}(\mathrm{b})$ and $k_{\text {cat }}(\mathrm{c})$. Different species are indicated in each figure, and continuous lines were obtained by nonlinear least-squares fitting of data according to Eq. (3) (a), Eq. (4) (b) and Eq. (5) (c). Parameters employed for each equation for the three species investigated are reported in Table 2. For further details, see the text.

decrease in substrate affinity (Fig. 4c), whereas the value of the rate-limiting step $k_{\text {cat }}$ tended to level off (Fig. $4 \mathrm{~b}$ and c).

In general terms, this feature indicated that low concentrations of MMP2 CBD enhanced but high concentrations of it inhibited the activity of MMP9, a behavior that could not be accounted for by a single binding process and suggests the existence of (at least) two types of binding sites of the CBD of MMP2 on collagen type IV. In particular, one binding site, which was characterized by a higher affinity, displayed a positive allosteric effect on the binding site of MMP9, increasing the substrate affinity for MMP9. The second binding site of the MMP2 CBD displayed a lower affinity and exerted a competitive inhibitory effect on the enzymatic action of MMP9 (as suggested by the fact that $k_{\text {cat }}$ is not affected by the interaction of MMP2 CBD with the second binding site; Fig. 4b), likely because it might closely overlap with the binding site of MMP9.

On the basis of these considerations, we described the allosteric equilibria according to Scheme 1, which can be applied to the enzymatic processing of each of the three investigated bands (i.e., 207, 169 and $92 \mathrm{kDa}$ ). These molecular forms of the substrate all displayed the same behavior (although characterized by different parameters; Table 3). The allosteric mechanism reported in Fig. 4 was described quantitatively by Eqs. (3)-(5) (Materials and Methods); continuous lines in Fig. 4 correspond to the curves obtained by nonlinear least-squares fitting of experimental data (reported in Table 3).

On the basis of this quantitative analysis, in the first allosteric binding step, CBD binding to its first high-affinity site (characterized by ${ }^{1} K_{\mathrm{bu}}$ and producing collagen IV-CBD; Scheme 1) brings about (i) an increased affinity of MMP9 for its binding site on type IV collagen (as from ${ }^{1} K_{\mathrm{m}}<{ }^{0} K_{\mathrm{m}}$; Table 3) and (ii) an enhanced rate for the substrate cleavage process (as from ${ }^{1} k_{\text {cat }}>{ }^{0} k_{\text {cat }}$; Table 3 ); the overall result is a marked increase in the catalytic efficiency of MMP9 [as from ${ }^{1}\left(k_{\text {cat }} / K_{\mathrm{m}}\right)>^{0}\left(k_{\text {cat }} / K_{\mathrm{m}}\right)$; Table 3]. Conversely, binding of CBD to the low-affinity site (characterized by ${ }^{2} K_{\text {bu }}$; Scheme 1) leads to the formation of collagen $\mathrm{IV}(\mathrm{CBD})_{2}$, which cannot be enzymatically processed by MMP9 due to the overlap between the second binding site of MMP2 CBD on collagen type IV and the primary binding site of MMP9.

In particular, the allosteric increase in the catalytic efficiency (as from $k_{\text {cat }} / K_{\mathrm{m}} ;$ Fig. 4 and Table 3 ) is only 2- or 3-fold for the 207- and 169-kDa species (i.e., for the $\alpha 1$ chain either intact or missing the N-terminal 7S domain). The positive allosteric effect on the $92-\mathrm{kDa}$ species (i.e., for the $\alpha 2$ chain, although missing the $\mathrm{N}$ terminal part) is somewhat more marked (i.e., about 10-fold). This behavior finds an explanation when we compare ${ }^{1} K_{\mathrm{bu}}$ and ${ }^{1} K_{\mathrm{bL}}$ (Table 3 ), which reflect the long-range functional influence between MMP9 binding and CBD binding at the two distinct sites (Schemes 1 and 2). Thus, while for the $\alpha 1$ chain (both intact and missing the N-terminal 7S domain) the effect is modest (being always less than a 2-fold enhancement; Table 2), for the $\alpha 2$ chain missing the N-terminal half (i.e., the $92-k D a$ species), we observed a more positive cooperative effect with more than a 4-fold increase for CBD affinity to the first site when MMP9 is bound to its binding pocket (i.e., for ${ }^{1} K_{b L}$ ).

Furthermore, from this analysis of data, the following emerge:

(i) The ligand-linked effect on the affinity of CBD for the first binding site (i.e., ${ }^{1} K_{\mathrm{bL}} /{ }^{1} K_{\mathrm{bu}}$ ) is very limited both for the intact $\alpha 1$ chain (i.e., the 207-kDa band) and the $\alpha 1$ chain missing the N-terminal $7 \mathrm{~S}$ domain (i.e., the 169-kDa band), being much less than a 


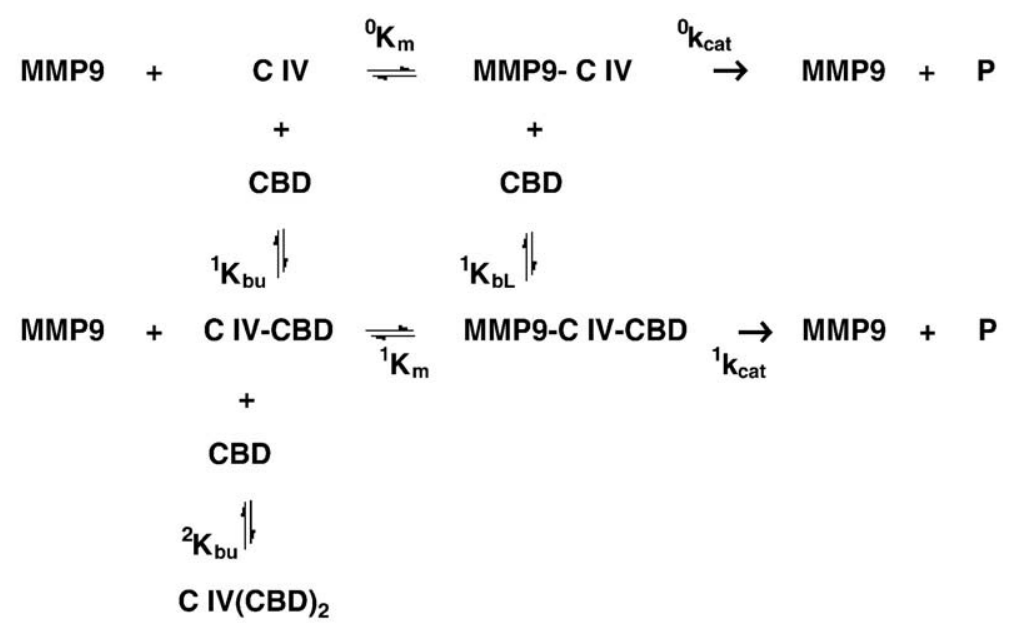

Scheme 1. Scheme of the allosteric cooperativity between MMP2 CBD (CBD) and MMP9 in collagen IV (C IV) degradation. "P" indicates the degradation product(s).

twofold affinity increase, whereas it is more pronounced for the $\alpha 2$ chain (i.e., the $92-\mathrm{kDa}$ fragment) (Table 3).

(ii) The ligand-linked effect related to the interaction of CBD with the first binding site can be observed on $k_{\text {cat }} / K_{\mathrm{m}}$ [i.e., $\left.{ }^{1}\left(k_{\text {cat }} / K_{\mathrm{m}}\right) /{ }^{0}\left(k_{\text {cat }} / K_{\mathrm{m}}\right)\right]$ for the $\alpha 2$ chain (with a 3 -fold increase in $k_{\text {cat }}$ and a 10-fold decrease in $K_{\mathrm{m}}$; Table 3 ) but is only moderate in the intact $\alpha 1$ chain (with a 2-fold increase in $k_{\text {cat }}$ and an almost 2-fold decrease in $K_{\mathrm{m}}$; Table 3), becoming almost undetectable when the 7S domain is removed; the second competitive binding site of CBD is characterized by a lower affinity with respect to the first binding site of the 207- and 169-kDa chains, but a closely similar affinity is observed for the two binding sites in the case of the 92-kDa fragment (Table 3).

\section{SPR analysis of CBD-collagen IV interactions}

The interaction between type IV collagen and MMP2 CBD, indirectly studied from the modulation of the MMP9 enzymatic activity by MMP2 CBD (Fig. 4), has also been directly measured by surface plasmon resonance (SPR) measurements. The kine-

Table 3. Catalytic and binding parameters from data analysis according to Scheme 1 and employing Eqs. (3)-(5)

\begin{tabular}{lccc}
\hline & $207 \mathrm{kDa}$ & $169 \mathrm{kDa}$ & $92 \mathrm{kDa}$ \\
\hline${ }^{0} k_{\mathrm{cat}} / K_{\mathrm{m}}\left(\mathrm{M}^{-1} \mathrm{~s}^{-1}\right)$ & $2.0 \pm 0.2 \times 10^{4}$ & $4.9 \pm 0.5 \times 10^{4}$ & $1.2 \pm 0.2 \times 10^{5}$ \\
${ }^{1} k_{\mathrm{cat}} / K_{\mathrm{m}}\left(\mathrm{M}^{-1} \mathrm{~s}^{-1}\right)$ & $6.5 \pm 0.7 \times 10^{4}$ & $7.9 \pm 0.9 \times 10^{4}$ & $1.2 \pm 0.2 \times 10^{6}$ \\
${ }^{0} K_{\mathrm{m}}(\mathrm{M})$ & $5.1 \pm 0.6 \times 10^{-4}$ & $2.9 \pm 0.3 \times 10^{-5}$ & $1.0 \pm 0.2 \times 10^{-5}$ \\
${ }^{1} K_{\mathrm{m}}(\mathrm{M})$ & $3.2 \pm 0.4 \times 10^{-4}$ & $2.4 \pm 0.3 \times 10^{-5}$ & $2.7 \pm 0.4 \times 10^{-6}$ \\
${ }^{0} k_{\mathrm{cat}}\left(\mathrm{s}^{-1}\right)$ & $10.2 \pm 1.6$ & $1.4 \pm 0.2$ & $1.2 \pm 0.2$ \\
${ }^{1} k_{\mathrm{cat}}\left(\mathrm{s}^{-1}\right)$ & $20.3 \pm 2.4$ & $1.9 \pm 0.2$ & $3.2 \pm 0.4$ \\
${ }^{1} K_{\mathrm{bu}}\left(\mathrm{M}^{-1}\right)$ & $8.1 \pm 0.9 \times 10^{5}$ & $3.7 \pm 0.4 \times 10^{5}$ & $7.5 \pm 0.8 \times 10^{4}$ \\
${ }^{2} K_{\mathrm{bu}}\left(\mathrm{M}^{-1}\right)$ & $2.0 \pm 0.2 \times 10^{4}$ & $5.6 \pm 0.6 \times 10^{3}$ & $9.0 \pm 1.1 \times 10^{4}$ \\
${ }^{1} K_{\mathrm{bL}}\left(\mathrm{M}^{-1}\right)$ & $1.3 \pm 0.2 \times 10^{6}$ & $4.3 \pm 0.5 \times 10^{5}$ & $2.8 \pm 0.5 \times 10^{5}$ \\
\hline
\end{tabular}

tic and equilibrium constants for CBD-collagen IV interactions were determined by SPR using typical binding assays, where different concentrations of type IV collagen (analytes) were allowed to bind the immobilized CBD as a function of time. The curves of the sensorgrams, reported in Fig. 5, clearly indicated biphasic interaction kinetics, which underlies the presence of two distinct binding sites of CBD on collagen IV, confirming the results derived from the effect of MMP2 CBD on MMP9 proteolytic activity toward type IV collagen (Fig. 4). The kinetic parameters and the resulting equilibrium constants for the two binding sites are reported in Table 4. Interestingly, although these two equilibrium constants refer to the interaction of immobilized CBD with collagen IV from human placenta and although we cannot distinguish which molecular component is contributing to either of the two processes, the values are quite similar to those obtained from the allosteric analysis for the isolated $\alpha 1$ and $\alpha 2$ chains (Tables 3 and 4).

\section{Effect of CBD on neutrophil migration across collagen IV}

To validate whether the collagen IV-mediated regulation of MMP9 by MMP2 inactive forms is biologically relevant, we tested this modulation in a cellbased system, trying to reproduce as closely as possible the experimental conditions of the biochemical investigation reported above. In Fig. 6, the effects of the MMP2 CBD on neutrophil chemokinesis across collagen IV coating are shown. Neutrophil migration increased upon the addition of lipopolysaccharide (LPS) as an activator for MMP release (histogram 1 versus histogram 2), which was associated with an enhancement of MMP9 secretion and activity (zymogram data not shown). The addition of exogenous active MMP2 brought about a concentration-dependent decrease in neutrophil migration (histograms 3 and 4 ), ${ }^{36}$ possibly due to the release of fragments with a biological inhibitory activity (i.e., 


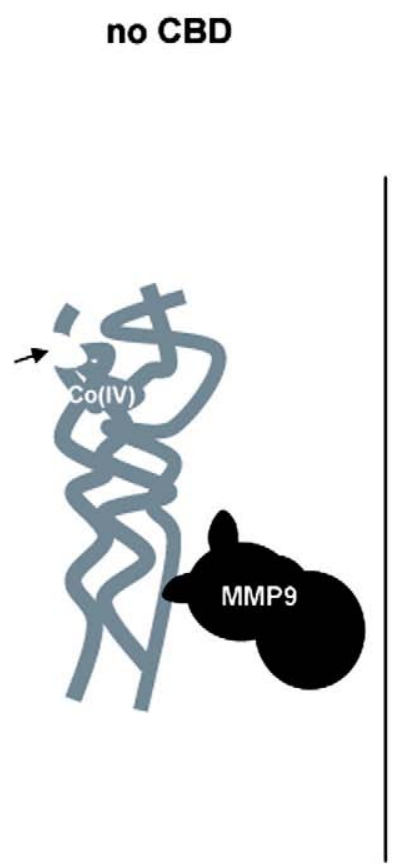

(a) low [CBD]

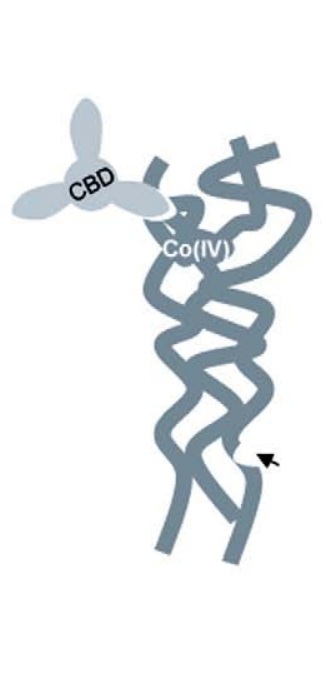

(b) high [CBD]

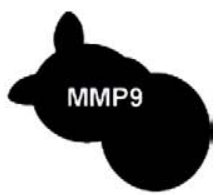

$\downarrow \uparrow$

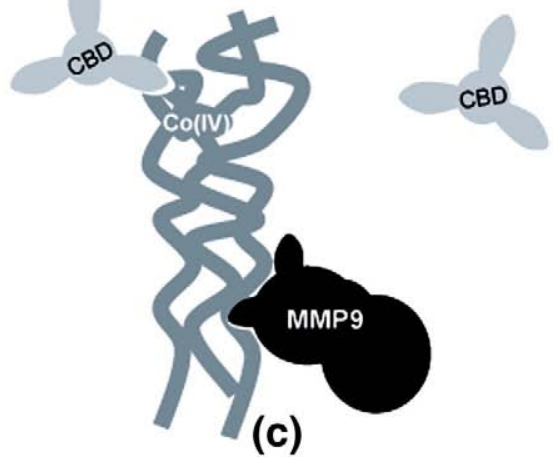

Scheme 2. Cartoon representation of the allosteric cooperativity between MMP2 CBD and MMP9 for collagen IV degradation. At low CBD concentrations, MMP2 CBD binds collagen IV at the high-affinity binding site (upper left, see panels A and B), inducing a conformational change of the binding site of MMP9 (lower right, see panels A and B), which facilitates MMP9-collagen IV interaction (see panels A and B). At higher CBD concentrations, a second CBD molecule can compete with MMP9 for the same binding site (see panel C).

antiangiogenic and antimigratory). ${ }^{24-26}$ The addition of either $5 \mu \mathrm{M}$ MMP2 CBD (histogram 5) or an inactive E402A mutant of MMP2 to a final concentra-

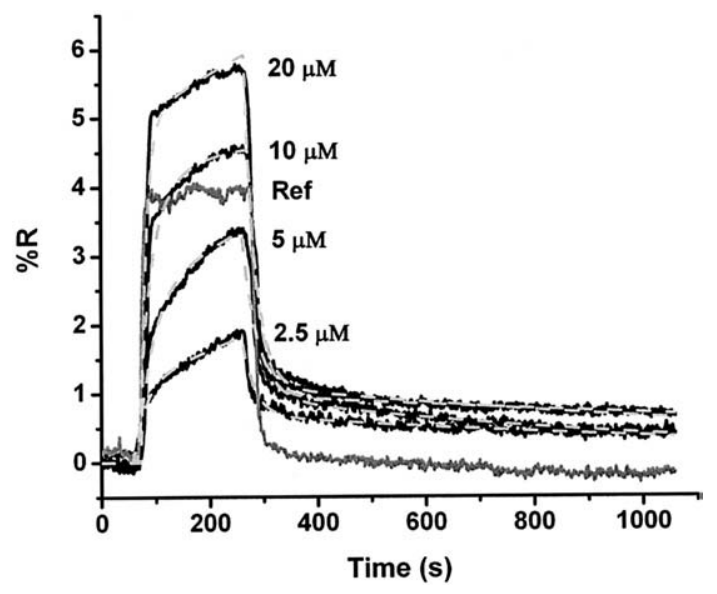

Fig. 5. SPRI sensorgrams of type IV collagen binding to immobilized MMP2 CBD. CBD was allowed to interact with different solutions of type IV collagen, and the binding was examined as described in Materials and Methods. Fitted lines according to the two binding site models are shown in dashed light gray lines, while the line indicated as reference (continuous dark gray line) is representative of the curves obtained by injecting type IV collagen solutions into microchannels without the immobilized MMP2 CBD. In the latter case, no appreciable interaction was recorded. tion of $4 \mu \mathrm{M}$ (histogram 7) induced a significant increase in neutrophil migration (histograms 5 and 7 versus histogram 2, likely related to the enhanced MMP9 activity; Fig. 3).

In the presence of $2.5 \mu \mathrm{M}$ pro-MMP2 (histogram 6 versus histogram 2 ), the enhancing effect on neutrophil migration almost disappeared, an effect possibly related to partial activation of the zymogen form in a cellular context (with consequent reduction of migration stimulation, which could counterbalance the expected increase in MMP9 activity related to the binding of pro-MMP2 to collagen IV). In parallel, similar experiments were performed employing matrigel and MMP inhibitors; no meaningful change for neutrophil chemokinesis was observed (data not shown), suggesting that the modulatory process is operative only with collagen IV.

\section{Discussion}

MMP9 is an MMP expressed and released by neutrophils ${ }^{41}$ and is involved in the "angiogenesis switch," ${ }^{42,43}$ in cancer progression, ${ }^{44,45}$ in vascular invasion $^{46}$ and in chronic inflammatory processes, including the autoimmune diseases multiple sclerosis and rheumatoid arthritis. ${ }^{47-49}$ Therefore, functional modulation of MMP9 enzymatic activity is of crucial importance for better comprehension of several pathological events. Previous findings sup- 
Table 4. Kinetic and equilibrium parameters for the interaction between MMP2 CBD and type IV collagen at $37^{\circ} \mathrm{C}$ by SPR

\begin{tabular}{lc}
\hline${ }^{\text {on }} k_{1}\left(\mathrm{M}^{-1} \mathrm{~s}^{-1}\right)$ & $1.06 \pm 0.19 \times 10^{3}$ \\
${ }^{\text {on }} k_{2}\left(\mathrm{M}^{-1} \mathrm{~s}^{-1}\right)$ & $3.09 \pm 0.50 \times 10^{1}$ \\
${ }^{\text {off }} k_{1}\left(\mathrm{~s}^{-1}\right)$ & $1.5 \pm 1.1 \times 10^{-2}$ \\
${ }^{\text {off }} k_{2}\left(\mathrm{~s}^{-1}\right)$ & $2.6 \pm 1.2 \times 10^{-2}$ \\
$K_{1}\left(\mathrm{M}^{-1}\right)$ & $7.07 \times 10^{4}$ \\
$K_{2}\left(\mathrm{M}^{-1}\right)$ & $1.19 \times 10^{3}$ \\
\hline
\end{tabular}

The equilibrium constants $(K)$ were calculated from the rate constants for association $\left({ }^{\text {on }} k\right)$ and dissociation $\left({ }^{\text {off }} k\right)$ from the equation, $K_{\mathrm{eq}}={ }^{\text {on }} k /{ }^{\text {off }} k$.

port the possibility that MMP8 and MMP9 form specific complexes in vivo, ${ }^{50}$ suggesting that the two MMPs actually cooperate. Furthermore, other investigators pointed out that, depending on the specific context, gelatinases could work either in concert or antagonistically. ${ }^{51,52}$ In particular, in the mechanism controlling leukocyte transendothelial migration, MMPs are suggested to facilitate this passage through the perivascular basement membrane. ${ }^{15}$ Given that gelatinases serve as enzymes for the degradation of type IV collagen, the most prominent component of venular basement membranes, ${ }^{21-25,53}$ we used collagen IV as a physiological substrate. Considering that previous studies on the MMP2 CBD ligand binding interaction have shown that the CBD is responsible for virtually all the collagen binding properties of MMP2,29,54 we aimed to determine whether MMP2 CBD modulates MMP9 catalytic activity toward collagen IV.

Enzymatic processing by gelatinases of three chain components from type IV collagen from human placenta (characterized by 207, 169 and $92 \mathrm{kDa}$ ) has been already reported. ${ }^{35,36}$ However, in this work, for the first time, we (i) assigned these chain components to intact $\alpha 1$ chain, $\alpha 1$ chain missing the N-terminal 7S domain and $\alpha 2$ chain missing the half N-terminal domain, respectively; (ii) quantitatively characterized the enzymatic mechanism of MMP9 concerning the cleavage step of collagen type IV and (iii) characterized the modulation of collagen IV degradation by MMP2 CBD.

A comparison between the catalytic behaviors of MMP2 and MMP9 (Table 2) shows that MMP2 is more efficient than MMP9 in degrading the $\alpha 1$ collagen IV chain at $37{ }^{\circ} \mathrm{C}$, a feature that can be wholly attributed to the lower affinity of MMP9 for collagen IV (as expressed by $K_{\mathrm{m}}$ Table 1 ). These differences in $K_{m}$ values can be explained by (i) a different interaction mode of the two enzymes (likely due to different conformations of the fibronectin-like domain between the two enzymes) and/or (ii) topologically distinct binding sites. This second interpretation is in agreement with the fact that the binding affinity of $\alpha 1$ chain for MMP2 remains essentially the same even in the absence of the 7S domain, while it is increased in the case of MMP9 (see Table 1, comparing parameters for the 207- and $169-\mathrm{kDa}$ bands). In other words, this suggests that the 7S domain interferes with the MMP9 substrate binding site but not with the MMP2 substrate binding site, thus implying that the two enzymes interact with different regions of the chain.

The interference and the consequently lower affinity of the enzyme for the substrate (i.e., $K_{\mathrm{m}}$ ) in the presence of the 7S domain are in line with the fact that the interaction of MMP9 with the $\alpha 1$ chain requires a conformational change of the substrate (likely involving the 7S domain) to expose the binding site. We observed that the increase in MMP9 affinity (i.e., $K_{\mathrm{m}}$ ) upon removal of the $\mathrm{N}$-terminal $7 \mathrm{~S}$ domain in the $\alpha 1$ chain is accompanied by a marked reduction in the rate-limiting step velocity $\left(k_{\text {cat }}\right)$ (Table 1$)$, indicating that the MMP9-induced conformational change in the intact $\alpha 1$ chain facilitates chain cleavage by MMP9.

This mechanism underlies the existence of ligandlinked long-range structural effects in collagen IV, and this is also clearly demonstrated by the synergic action exerted by the MMP2 CBD on the enzymatic action of MMP9 on collagen IV (Figs. 3 and 4 and Scheme 2). In particular, Fig. 4a shows that the first type of binding site, which acts synergistically with MMP9, is characterized by a higher affinity, whereas only at higher concentrations does CBD become able to bind a second type of site, thus competing with MMP9 and inducing a decrease in the overall catalytic activity. These features imply that (i) the highaffinity binding site is topologically distinct from that of MMP9 and (ii) binding of CBD to this site induces a conformational change of the chains, which renders it more susceptible to proteolytic attack by MMP9. On the other hand, the second binding site, characterized by a lower affinity, has an inhibitory effect on MMP9 activity, likely because it

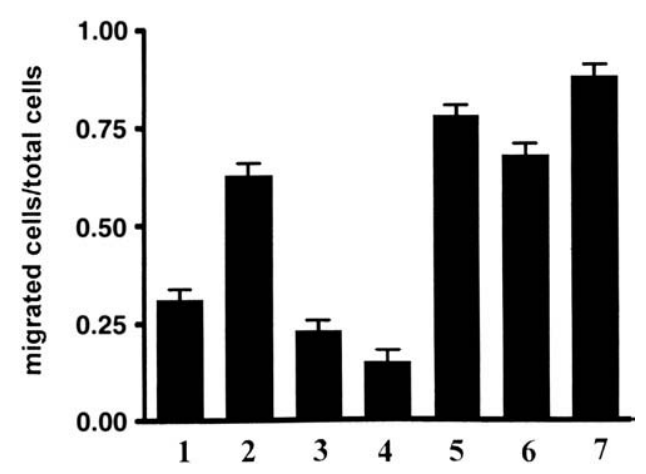

Fig. 6. Neutrophil migration across collagen type IV at $37^{\circ} \mathrm{C}$. Results are presented as a percentage of migrated cells versus total cells. The relative extent of neutrophil migration to the lower chamber is reported for cells containing control buffer (histogram 1), in the presence of $500 \mathrm{ng} / \mathrm{ml}$ of LPS (histogram 2), in the presence of $500 \mathrm{ng} / \mathrm{ml}$ of LPS and $1 \mathrm{nM}$ active MMP2 (histogram 3), in the presence of $500 \mathrm{ng} / \mathrm{ml}$ of LPS and $40 \mathrm{nM}$ active MMP2 (histogram 4), in the presence of $500 \mathrm{ng} / \mathrm{ml}$ of LPS and $5 \mu \mathrm{M}$ CBD (histogram 5), in the presence of $500 \mathrm{ng} / \mathrm{ml}$ of LPS and $2.5 \mu \mathrm{M}$ pro-MMP2 (histogram 6) and in the presence of $500 \mathrm{ng} / \mathrm{ml}$ of LPS and $4 \mu \mathrm{M}$ inactive E402N MMP2 mutant (histogram 7). Neutrophil migration was measured as described in Materials and Methods. 
overlaps (at least partially) with the binding site of MMP9. It is interesting to observe that the interaction of MMP2 and MMP9 with collagen IV is drastically different from that reported for collagen I, where it has been suggested that the binding sites of the two gelatinases overlap. ${ }^{31,32}$

This phenomenon suggests that in the case of type IV collagen, the two gelatinases can cooperate not only in a concurrent degradation (if they proteolytically attack together the collagen IV at different binding and cleavage sites) but also allosterically in the absence of the enzymatic activity of either of the two gelatinases, since, as reported in this article, even the enzymatically inactive CBD (a domain of MMP2) is able to cooperate with MMP9 in processing collagen IV and favoring the neutrophil migration.

As a whole, MMP9 and MMP2 display drastically different behaviors in collagen IV processing, particularly for the binding of substrates. Thus, although the two CBDs share a high level of homology, structural differences are evident between the two gelatinases, since only the MMP2 CBD has been reported to efficiently bind collagen IV. ${ }^{31,36}$ Likewise, MMP2 has a much higher affinity for collagen IV than MMP9 (Table 1). On the basis of the linkedfunction analysis reported here, we show that the CBD-collagen IV binding is also important for enzymatic tuning. We propose that the $\alpha 1$ chain represents the first binding site (highest affinity) for MMP2, inducing a meaningful increase in the binding affinity of MMP9 toward the $\alpha 2$ chain (Table 3). The binding of CBD of MMP2 (and likely the whole enzyme) to the $\alpha 1$ chain has only a limited effect on the interaction of MMP9 with the same chain (Table 3), suggesting that the ligand-linked conformational change does not involve the homologous chain and is mostly transmitted to the partner chain. Higher concentrations of MMP2 CBD also lead to the occupancy of a second binding site (lower affinity), likely located on the $\alpha 2$ chain, that (at least partially) overlaps with that of MMP9, bringing about a competitive inhibition of the MMP9 binding and enzymatic activity (Figs. 3 and 4 and Scheme 2). In this respect, the direct CBDcollagen IV interaction assays, performed by SPR (Fig. 5), indeed confirm the presence of two distinct binding sites of MMP2 CBD on type IV collagen, although the observed phenomenon corresponds to the overall process and does not allow discrimination of which is the chain interacting with CBD. However, considering that the immobilized CBD could interact somewhat differently with collagen IV by SPR and in solution, the values reported in Table 4 as $K_{1}$ and $K_{2}$ could correspond to the binding of $\mathrm{CBD}$ to the $\alpha 1$ chain and that to the $\alpha 2$ chain, respectively.

Therefore, the mutual effects of the two binding sites of MMP2 CBD and those of MMP9 may represent an important clue for the mechanism operative in vivo on collagen IV, as indicated by the fact that inactive forms of MMP2 induce a marked enhancement of the neutrophil migration across a collagen
IV model membrane (Fig. 6). In this respect, it is worth outlining that while the fully inactive MMP2 (i.e., either the CBD alone or the inactive mutant E402N) favors the neutrophil extravasation (Fig. 6), the activation of MMP2 brings about a reduction of this pro-inflammatory response. It is interesting to observe that pro-MMP2, which should facilitate the neutrophil extravasation, displays only a vanishingly small increase in neutrophil migration, possibly because of a partial activation of the zymogen. Therefore, active MMP2 seems to act as an antiinflammatory factor that counterbalances the action of MMP9 on the neutrophil extravasation, underlying the possibility that a fine modulation of the active-inactive levels of MMP2 is a crucial aspect of the whole cellular response. Such observation is in line with in vivo data with MMP2- and MMP9deficient mice in an antibody-induced arthritis model. ${ }^{52}$ This phenomenon raises important questions on the actual efficacy in vivo of selective inhibition of MMPs, including the possibility of paradoxical effects, where inhibition of MMP2 potentiates the enzymatic action of MMP9. Therefore, a rethinking of inhibitor design strategy is required, as proteinases do not act alone, but in cascades or circuits and networks that all dynamically interconnect to form the protease web. ${ }^{1}$

\section{Materials and Methods}

\section{Materials}

As commonly reported in the literature, type IV collagen from human placenta (Sigma Chemical, St. Louis, $\mathrm{MO}$ ) was dissolved in $0.1 \mathrm{M}$ acetic acid at room temperature to a final concentration of $1 \mathrm{mg} / \mathrm{ml}$. The suspension was centrifuged for $1 \mathrm{~h}$ at $10,000 \mathrm{~g}$, and the supernatant containing the solubilized collagen was used. The amount of substrate has been quantified as described by Bradford. ${ }^{55}$ Sequencing-grade trypsin was purchased from Promega (München, Germany).

Recombinant human full-length MMP9 was produced in Sf9 insect cells after transfection with a baculovirus carrying the MMP9 cDNA. ${ }^{4}$ The secreted pro-MMP9 was purified to homogeneity by gelatin-Sepharose chromatography $^{56}$ and dialyzed into $100 \mathrm{mM}$ Tris- $\mathrm{HCl}$, $\mathrm{pH} 7.4,100 \mathrm{mM} \mathrm{NaCl}$ and $10 \mathrm{mM} \mathrm{CaCl}_{2}$. The proenzyme was activated by incubating $10 \mu \mathrm{M}$ progelatinase solution with a solution of $0.1 \mu \mathrm{M}$ cdMMP3 (Biomol International, USA) at $37{ }^{\circ} \mathrm{C}$ for $90 \mathrm{~min}$.

The solution of purified recombinant CBD of MMP2 was obtained as previously reported. ${ }^{29}$ The correct folding of CBD was tested by SDS-PAGE, ${ }^{57}$ loading a small amount of CBD eluted from a small gelatin-Sepharose column (Sigma Chemical). ${ }^{32}$

For neutrophil migration assay, Falcon 24-well plates containing transwell inserts were used (Becton Dickinson Labware, San Jose, CA). LPS W from Escherichia coli and Ficoll solution were purchased from DIFCO Laboratories (Detroit, MI). Orthophenylendiamine (OPD) was purchased from Sigma Chemical. The quenched fluorogenic substrate MCA [(7-methoxycoumarin-4-yl) acetyl]-Pro-Leu-Gly-Leu-DPA [N-3-(2,4-dinitrophenyl)-L2,3-diaminopropionyl]-Ala-Arg- $\mathrm{NH}_{2}$ was purchased from Calbiochem (La Jolla, CA). 


\section{Edman sequencing}

Eight micrograms of collagen IV from human placenta (Sigma Chemical) was separated by reducing SDS-PAGE and blotted onto a polyvinylidene fluoride membrane. The membrane was stained with Coomassie Brilliant Blue R250 and destained. The 92-kDa band was excised and sequenced on a capillary protein sequencer (Procise 491 cLC, Applied Biosystems, Foster City, CA).

\section{Trypsin in-gel digestion}

The in-gel digestion of pepsinized collagen IV was performed using a procedure that has been previously described. ${ }^{58}$ Unless otherwise noted, the various steps of the procedure were performed at room temperature and all incubation steps were performed under shaking conditions. After SDS-gel electrophoresis and Coomassie Blue staining, the protein bands of interest in the SDS gel were excised, cut into small pieces $(1 \times 1 \mathrm{~mm})$, transferred into a $0.5-\mathrm{ml}$ polyethylene sample vial and washed with $200 \mu 1$ of nanopure water. The SDS-gel pieces were destained by incubation with $50 \mu$ of HPLC-grade acetonitrile for $5 \mathrm{~min}$. The supernatant was then discarded and $50 \mu \mathrm{l}$ of deionized water was added to the SDS-gel pieces. The last two steps were repeated until the SDS-gel pieces were completely transparent. The supernatant was removed and the SDS-gel pieces were incubated with $100 \mu \mathrm{l}$ of acetonitrile for $5 \mathrm{~min}$. After the gel pieces were dried, the SDS-gel pieces were

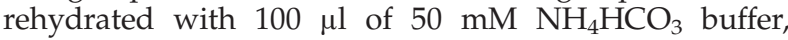
$\mathrm{pH}$ 8.5.

The SDS-gel pieces were then shrunk with $50 \mu \mathrm{l}$ of HPLC-grade acetonitrile and rehydrated with reducing buffer $\left(10 \mathrm{mM}\right.$ DTT in $\left.100 \mathrm{mM} \mathrm{NH} \mathrm{NCO}_{3}\right)$ for $30 \mathrm{~min}$ at $56{ }^{\circ} \mathrm{C}$. After the supernatant was discarded, gel pieces were dehydrated with acetonitrile and successively rehydrated with alkylating buffer $(55 \mathrm{mM}$ iodoacetamide in $100 \mathrm{mM} \mathrm{NH}_{4} \mathrm{HCO}_{3}$ ) for $20 \mathrm{~min}$ at room temperature in the dark. Gel species were shrunk again with acetonitrile and then finally rehydrated with $20 \mu \mathrm{l}$ of ice-cold digestion solution $(10 \mathrm{ng} / \mathrm{ml}$ of sequencing-grade trypsin in $50 \mathrm{mM} \mathrm{NH} \mathrm{HCO}_{3}, \mathrm{pH}$ 8.0) for $20 \mathrm{~min}$ on ice after removing the supernatant. The unabsorbed trypsin solution was replaced with $22 \mu \mathrm{l}$ of $50 \mathrm{mM} \mathrm{NH}_{4} \mathrm{HCO}_{3}$ buffer, $\mathrm{pH} 8.0$, and finally incubated at $37^{\circ} \mathrm{C}$ overnight. Resulting peptide fragments were extracted from the gels in two steps: (i) $50 \mu \mathrm{l}$ of acetonitrile was added to the tubes and sonicated for $15 \mathrm{~min}$ at $37^{\circ} \mathrm{C}$, and the supernatant was collected in a clean tube and the SDS-gel pieces were then hydrated with $50 \mu \mathrm{l}$ of $5 \%(\mathrm{v} / \mathrm{v})$ formic acid at $37{ }^{\circ} \mathrm{C}$ for $15 \mathrm{~min}$, and (ii) the second elution step was performed by adding $50 \mu \mathrm{l}$ of acetonitrile and incubating in a sonication bath at $37^{\circ} \mathrm{C}$ for $15 \mathrm{~min}$. The supernatant was collected and combined with the first peptidic extractions. The pooled extract was concentrated in a vacuum centrifuge down to $5 \mu \mathrm{l}$. Samples underwent a C18 cleaning step using C18 STAGE tips. ${ }^{59}$

\section{Mass spectrometry}

Desalted tryptic peptide samples $(0.5 \mu \mathrm{l})$ were mixed with $0.4 \mu \mathrm{l}$ of CCA-matrix (3-hydroxyalpha-cyano-cinnamicacid; saturated solution in $50 \%$ acetonitrile $/ 0.1 \%$ trifluoroacetic acid), and spotted onto a steel matrix-assisted laser desorption/ionization plate (J. T. Baker, Phillipsburg, MA). The deposited mixture was allowed to dry before introduc- tion into the mass spectrometer. Three independent measurements were taken for each sample. Calibration mixture peptides from a Peptide Mass Standard Kit (Applied Biosystems, Welterstadt, Germany; Bruker Daltonics, Bremen, Germany) were used for plate alignment and external calibration of both MS and MS/MS.

MS measurements were performed on a tandem time-offlight mass spectrometer (4700 Proteomics Analyzer, Applied Biosystems) operating in reflector positive ion mode. The 10 most intense peaks of MS1 spectra were fragmented using collision-induced dissociation CID in atmospheric gas.

\section{Database searching: peptide mass fingerprinting and MS/MS ion search}

Protein identification and peptide identification were performed through automated database searching. The analysis concurrently considered MS and MS/MS spectra; their extracted peak lists were used for protein identification by matching them to the theoretical spectra in silico generated from the entire human National Center of Biotechnology Information protein database (FASTA format). MS analysis was performed with GPS Explorer ${ }^{\mathrm{TM}}$ software (Applied Biosystems) using MASCOT ${ }^{\mathrm{TM}}$ (Matrix Science, London, UK) database searching engine.

All tandem mass spectra were searched against the entire human National Center of Biotechnology Information database. Carbamidomethyl (Cys) was chosen as the fixed modification, and oxidized methionine and hydroxylated lysine and proline were searched as the variable modifications. Searches were done with trypsin cleavage specificity allowing three missed cleavages; mass tolerance for monoisotopic peptide identification was set to $100 \mathrm{ppm}$, and that for fragment ions was set to 0.6 Da.

\section{Activity assay}

The active amount of the enzyme MMP9 was determined by gelatin zymography and by the fluorometric titration assay, as described by others, ${ }^{60}$ following the progressive decrease in hydrolysis of the quenched fluorogenic substrate MCA-Pro-Leu-Gly-Leu-DPA-Ala-Arg$\mathrm{NH}_{2}$ upon addition of batimastat (BB-94), a peptidomimetic inhibitor (kindly provided by British Biotech Pharmaceutical, Cowley, Oxford, UK) that stoichiometrically inhibits MMPs.

\section{Kinetics of digestion of collagen type IV}

For substrate fragmentation kinetics, active MMP9 was added to collagen type IV solutions at a final concentration of $30 \mathrm{pM}$. Kinetic analyses were carried out in $50 \mathrm{mM}$ Tris$\mathrm{HCl}, 0.1 \mathrm{M} \mathrm{NaCl}$ and $10 \mathrm{mM} \mathrm{CaCl}{ }_{2}, \mathrm{pH} 7.1$, employing different concentrations of collagen type IV (spanning between 1 and $3 \mu \mathrm{M}$ ). Kinetics was carried out keeping the mixtures at $37{ }^{\circ} \mathrm{C}$ and harvesting small aliquots at different time intervals. Reactions were stopped by the addition of SDS-PAGE loading buffer containing $20 \mathrm{mM}$ EDTA (ethylenediaminetetraacetic acid) and frozen to $-80{ }^{\circ} \mathrm{C}$ until used.

The aliquots in reducing sample buffer were separated on $4 \%-15 \%$ gradient SDS-PAGE gels, which were stained with $0.5 \%$ Coomassie Blue and destained in $10 \%$ acetic acid and $40 \%$ methanol until substrate bands were clearly visible. The broad- and low-spectrum protein markers (BioRad, USA) were used as molecular weight standards. 


\section{Modulation of the CBD of MMP2 on the processing of collagen type IV by MMP9}

Different concentrations of the fibronectin-like domain of MMP2 (CBD) (spanning between a final concentration of $1 \mu \mathrm{M}$ and that of $150 \mu \mathrm{M}$ ) were incubated with collagen type IV from human placenta $(1 \mathrm{mg} / \mathrm{ml})$ for $30 \mathrm{~min}$ at $37^{\circ} \mathrm{C}$ to allow the interaction to occur. Active MMP9 was then added to the CBD-collagen IV solution to a final concentration of $30 \mathrm{pM}$. The enzymatic reaction was carried out for $30 \mathrm{~min}$ at $37^{\circ} \mathrm{C}$. In parallel, three control samples were prepared: (i) collagen type IV alone, (ii) collagen type IV incubated for the same time interval with MMP9 at $37{ }^{\circ} \mathrm{C}$ and (iii) a solution of collagen type IV with the respective concentration of CBD but without MMP9. Reactions were stopped by the addition of SDS-PAGE loading buffer containing $20 \mathrm{mM}$ EDTA and frozen to $-80{ }^{\circ} \mathrm{C}$ until used. The different proteins were visualized after SDS-PAGE by Coomassie Blue staining.

\section{Kinetic analysis}

Coomassie Blue-stained electrophoretic bands, corresponding to different aliquots at different time intervals, were analyzed by a laser densitometer (LKB 2202 UltraScan). Much attention was paid to employ and measure only amounts of collagen within the linearity of the standard curve. Their intensity was thus calibrated (in order to obtain concentration values) using standard substrate solutions. It must be pointed out that different preparations of native type IV collagen or type IV collagen from human placenta displayed differing ratios of the relative amount of the species, as from the intensity of electrophoretic bands on SDS-PAGE under reducing conditions. For the different species, the substrate disappearance rates were derived at each type IV collagen concentration employed.

The measurement of the initial velocity was referred to a period of $1 \mathrm{~h}$ for type IV collagen from human placenta. During these intervals, less than $10 \%$ of the substrate was degraded in the assay, and in any case, the analysis was limited to the time interval over which linearity of the rate was observed. This ensured a steady-state condition for the first cleavage step, and it was a prerequisite for the subsequent analysis step. This consisted of the verification for the applicability of the Michaelis-Menten approximation to the first cleavage step, which was based on the observation of an inverse linear correlation between velocity and substrate concentration according to the Lineweaver-Burk equation. In order to obtain the catalytic parameters $k_{\text {cat }}$ and $K_{\mathrm{m}}$, we simultaneously fitted data to the Lineweaver-Burk equation

$$
\frac{E_{0}}{v}=\frac{K_{m}}{k_{\mathrm{cat}}} \cdot \frac{1}{[S]}+\frac{1}{k_{\mathrm{cat}}}
$$

and to the Eadie-Hofstee equation

$$
\frac{v}{E_{0}}=k_{\mathrm{cat}}-\frac{v}{E_{0} \cdot[\mathrm{S}]} \cdot K_{m}
$$

where $E_{0}$ is the total enzyme concentration, $v$ is the actual rate (expressed as molar per second), $K_{\mathrm{m}}$ is the Michaelis-Menten equilibrium constant (expressed as molar), $k_{\text {cat }}$ is the rate-limiting step kinetic constant (expressed in per-second units) and [S] is the substrate concentration.

\section{Analysis of the allosteric scheme}

The reactions of Scheme 1 were converted to a system of ordinary differential equations by applying mass action kinetics (Eqs. (3)-(5)). These equations express the rate of change in concentration of each species based on Scheme $1 .{ }^{61}$ The parameters for these reactions were obtained by the nonlinear least-squares fitting of experimental data

$$
\begin{aligned}
& { }^{o b s} k_{c a t} / K_{m}=\frac{\left({ }^{0} k_{c a t} / K_{m}\right)+\left({ }^{1} k_{c a t} / K_{m}\right) \cdot{ }^{1} K_{\mathrm{bu}} \cdot[\mathrm{CBD}]}{1+{ }^{1} K_{\mathrm{bu}} \cdot[\mathrm{CBD}]+{ }^{1} K_{\mathrm{bu}} \cdot{ }^{2} K_{\mathrm{bu}} \cdot[\mathrm{CBD}]^{2}} \\
& { }^{o b s} \mathrm{~K}_{\mathrm{m}}={ }^{0} \mathrm{~K}_{\mathrm{m}} \cdot \frac{1+{ }^{1} \mathrm{~K}_{\mathrm{bu}} \cdot[\mathrm{CBD}]+{ }^{1} \mathrm{~K}_{\mathrm{bu}} \cdot{ }^{2} \mathrm{~K}_{\mathrm{bu}} \cdot[\mathrm{CBD}]^{2}}{1+{ }^{1} \mathrm{~K}_{\mathrm{bL}} \cdot[\mathrm{CBD}]+{ }^{1} \mathrm{~K}_{\mathrm{bL}} \cdot{ }^{2} \mathrm{~K}_{\mathrm{bL}} \cdot[\mathrm{CBD}]^{2}} \\
& { }^{o b s} k_{\mathrm{cat}}=\frac{\mathrm{k}_{\mathrm{cat}}+{ }^{1} \mathrm{k}_{\mathrm{cat}} \cdot{ }^{1} \mathrm{~K}_{\mathrm{bL}} \cdot[\mathrm{CBD}]}{1+{ }^{1} \mathrm{~K}_{\mathrm{bL}} \cdot[\mathrm{CBD}]}
\end{aligned}
$$

where ${ }^{0} k_{\text {cat }} / K_{\mathrm{m}}$ and ${ }^{1} k_{\text {cat }} / K_{\mathrm{m}}$ in Eq. (3) are the values of the catalytic efficiency of MMP9 toward the substrate in the absence of CBD and to substrate bound by CBD at the first allosteric binding site (i.e., C IV-CBD in Scheme 1). It is worth outlining that ${ }^{2} k_{\text {cat }} / K_{\mathrm{m}}=0$ since Scheme 1 implies that the second binding site of CBD induces competitive inhibition and MMP9 is inactive on collagen IV(CBD) $)_{2}$. ${ }^{1} K_{\mathrm{bu}}$ and ${ }^{2} K_{\mathrm{bu}}$ in Eq. (3) are the association binding constants for CBD to the two sites on the substrate in the absence of the enzyme, and they have the same meaning in Eq. (4), where ${ }^{0} K_{m}$ is the Michaelis-Menten constant in the absence of CBD. ${ }^{1} K_{\mathrm{bL}}$ in Eqs. (4) and (5) is the association binding constant for CBD to the first allosteric site on the substrate when the enzyme is bound; Scheme 1 implies that ${ }^{2} K_{\mathrm{bL}}=0$ since CBD cannot bind the second site when MMP9 is bound to the substrate (i.e., to the species MMP9-C IV-CBD; Scheme 1). In Eq. (5), ${ }^{0} k_{\text {cat }}$ and ${ }^{1} k_{\text {cat }}$ are the values for the rate-limiting step of MMP9 toward the enzyme-substrate complex in the absence of CBD (i.e., MMP9-C IV) and to the enzyme-substrate bound by $\mathrm{CBD}$ at the first allosteric binding site (i.e., MMP9-C IV-CBD), respectively.

\section{SPR experiment}

The SPR imaging (SPRI) apparatus (GWC Technologies, USA) was the same as that reported in our previous work. ${ }^{62}$ Microfluidic channels were fabricated in poly(dimethylsiloxane) (PDMS) polymer. Briefly, PDMS microchannels having a volume of about $0.7 \mu 1$ were created by replication from masters in polyvinyl chloride, with a pattern of parallel microchannels (depth $=80 \mu \mathrm{m}$; length $=1.4 \mathrm{~cm}$; width $=400 \mu \mathrm{m})$, featuring circular reservoirs (diameter $=400 \mu \mathrm{m}$ ) at both ends of each channel. A five-microchannel microfluidic device was used in this case for following the interaction between immobilized MMP2 CBD and type IV collagen at different concentrations. PEEK tubes (Upchurch Scientific) were inserted in such reservoirs in order to connect the PDMS microfluidic cell to a Masterflex L/S (Cole-Parmer, USA) peristaltic pump operating at $100 \mu \mathrm{l} / \mathrm{min}$. Replicas were formed from a 1:10 mixture of PDMS curing agent and prepolymer (Sylgard 184, Dow Corning, USA). The mixture was degassed under vacuum and then poured onto the master in order to create a layer with a thickness of about $3-4 \mathrm{~mm}$. The 
PDMS was then cured for at least $2 \mathrm{~h}$ at $60{ }^{\circ} \mathrm{C}$ before it was removed from the masters.

SPR images were analyzed by using the $\mathrm{V}^{++}$software (version 4.0, Digital Optics Limited, New Zealand) and the software package Image J 1.32j (National Institutes of Health, USA). SPRI provides data in pixel intensity units (0-255 scale). Data were converted into percentages of reflectivity $(\% R)$ by using the formula,

$$
\% R=100 *\left(0.85 I_{\mathrm{p}} / I_{\mathrm{s}}\right)
$$

where $I_{\mathrm{p}}$ and $I_{\mathrm{s}}$ refer to the reflected light intensity detected using p-polarized light and s-polarized light, respectively. The experiments were carried out by sequentially acquiring 15 frame-averaged SPR images with a 1-s delay between one another. Kinetic data were obtained by plotting the differences in the percentage of reflectivity $(\% R)$ from selected regions of interest of the SPR images as a function of time. All SPRI experiments were carried out at room temperature.

MMP2 CBD was immobilized onto Au (111) by using a two-step procedure. First, bare gold chips were incubated with dithiobis (succinimidylpropionate) (Lomant's reagent) $[0.0097 \mathrm{~g}$ in $2 \mathrm{ml}$ of DMSO (dimethyl sulfoxide Sigma-Aldrich] for $48 \mathrm{~h}$ under inert atmosphere. The surface so treated was washed with pure DMSO and high-purity water (Milli-Q Element Ultrapure Water) and could react directly with MMP2 CBD. N-(2-Hydroxyethyl)piperazine- $N^{\prime}$-(2-ethanesulfonic acid) sodium salt (0.01 M Hepes and 0.15 M NaCl, pH 7.4; HBS-N, Biacore International) (hereafter referred to as HBS-N buffer) was mixed with the appropriate volume of protein mother solution in order to obtain a final concentration of $6 \mu \mathrm{M}$. This solution was then left in contact with the prefunctionalized gold surface for about $30 \mathrm{~min}$. After the anchorage of MMP2 CBD, the substrate was washed with HBS-N buffer and ethanolamine- $\mathrm{HCl} 1 \mathrm{M}$ (SigmaAldrich) was used for deactivation of the unreacted NHS groups. The HBS-N buffer has been verified to be the best buffer to obtain a satisfying protein surface coverage for type IV collagen binding assays (about $4.2 \times 10$ 13 molecules $/ \mathrm{cm}^{2}$ ). After type IV collagen interaction, immobilized MMP2 CBD could be recycled for other SPRI analyses by flowing buffered solution onto the surface for about $20 \mathrm{~min}$ to achieve complete dissociation and to restore the SPRI baseline. The rate constants reported in Table 4 were calculated by fitting adsorption/desorption kinetic data through numerical integration analysis. ${ }^{63}$ However, these values are meaningful only if the reaction is not limited by ligand diffusion. In our case, the dimensions of the above-described microchannels ensured that, at the flow rate used in our SPRI experiments for the interaction between MMP2 CBD and type IV collagen $(100 \mu \mathrm{l} / \mathrm{min})$, the value describing the diffusion of collagen to the gold surface was about $10^{8}$ $\left(\mathrm{M}^{-1} \mathrm{~S}^{-1}\right)$, which is far above the rate constant values reported in Table 4; therefore, the results obtained are not affected by diffusion problems.

\section{Isolation of human neutrophils}

Neutrophils were isolated from healthy donors who volunteered. Whole blood was diluted [blood/phosphate-buffered saline (PBS) ratio=1:4] and stratified on Ficoll separating solution and then centrifuged at $1400 \mathrm{rpm}$ for $30 \mathrm{~min}$ at $4{ }^{\circ} \mathrm{C}$. Plasma and mononuclear cells were then removed by aspiration, and the red blood cells were lysed by adding $18 \mathrm{ml}$ of ice-cold water for
$30 \mathrm{~s}$; thereafter, $2 \mathrm{ml}$ of $10 \times$ PBS was added and the suspension was centrifuged ( $1600 \mathrm{rpm}$ for $5 \mathrm{~min}$ at $4{ }^{\circ} \mathrm{C}$ ) in order to remove red blood cell membrane debris and hemoglobin.

The neutrophil-containing pellet was then washed twice at $1600 \mathrm{rpm}$ for $5 \mathrm{~min}$ at $4{ }^{\circ} \mathrm{C}$ and resuspended in RPMI 1640 (EuroClone) medium supplemented with bovine serum albumin $(0.2 \%)$ to a final concentration of $4 \times 10^{6}$ cells $/ \mathrm{ml}$.

The viability of purified cells was measured by trypan blue dye exclusion count, and it was always found to be $>95 \%$.

\section{Migration assay}

Human neutrophil chemokinesis was analyzed as previously described. ${ }^{36}$ Falcon 24 -well plates containing transwell inserts with $3.0-\mu \mathrm{m}$ pore diameter were used. Transwell inserts were coated overnight at $4{ }^{\circ} \mathrm{C}$ (alternatively, $4 \mathrm{~h}$ at $37^{\circ} \mathrm{C}$ ) with either type IV collagen from human placenta or matrigel as previously described. ${ }^{64}$

Lower chambers were filled with $500 \mu$ l of RPMI 1640 medium containing $0.2 \%$ bovine serum albumin. To different wells, we added the following compounds: LPS to a final concentration of $500 \mathrm{ng} / \mathrm{ml}$ as a positive control; $500 \mathrm{ng} / \mathrm{ml}$ of LPS and exogenous MMP2 at two different concentrations (1 and $40 \mathrm{nM}) ; 500 \mathrm{ng} / \mathrm{ml}$ of LPS and $5 \mu \mathrm{M}$ $\mathrm{CBD} ; 500 \mathrm{ng} / \mathrm{ml}$ of LPS and $2.5 \mu \mathrm{M}$ pro-MMP2; and $500 \mathrm{ng} / \mathrm{ml}$ of LPS and the inactive E402N MMP2 mutant at a final concentration of $4 \mu \mathrm{M}$.

After placing the inserts into the wells, the upper chamber was filled with $500 \mu \mathrm{l}$ of neutrophils $\left(10^{6}\right.$ cells / well). Cells were allowed to transmigrate for $4 \mathrm{~h}$ at $37{ }^{\circ} \mathrm{C}$ in a humidified $5 \% \mathrm{CO}_{2}$ incubator. The transwell inserts were removed after washing the lower part of the membrane, and the bottom solution was collected and centrifuged in order to evaluate the transmigrated cells. Cell pellets were then suspended in a solution containing Triton X-100 to a final concentration of $0.5 \%$, $600 \mu \mathrm{g} / \mathrm{ml}$ of OPD and $6 \mu \mathrm{l} / \mathrm{ml}$ of $\mathrm{H}_{2} \mathrm{O}_{2}$ in $1 \times$ PBS. Diluted concentrations of neutrophils, from $10^{6}$ to $6 \times 10^{4}$ cells/well were used to obtain a standard curve. The oxidation of OPD performed by myeloperoxidase contained in neutrophils was stopped by adding $40 \mu \mathrm{l}$ of $2 \mathrm{M} \mathrm{HCl}$. Absorbance at $492 \mathrm{~nm}$ was measured with a spectrophotomer (Jasco V-530). Each experiment was performed in at least three technical replicates and two biological replicates (two bleeds from different healthy donors).

\section{Acknowledgements}

Financial support from the Italian Ministry of University and Research (MiUR COFIN 2003058409 to M.C.) and that from the Italian Space Agency (ASI 2005 OSMA to M.C.) are gratefully acknowledged. This study was also supported by the Geconcerteerde Onderzoeksacties (GOA 20062010), the Fund for Scientific Research-Flanders (FWO-Vlaanderen) and governmental financing for the Rega Institute and Centre of Excellence (Belgium; EF 05/15). P.V.D.S. is a postdoctoral fellow of FWO-Vlaanderen. We thank Prof. Paul Proost of the 
Rega Institute for his help with protein sequencing and Profs. Giuseppe Spoto and Enrico Rizzarelli for fruitful discussions.

\section{References}

1. Overall, C. M. \& Blobel, C. P. (2007). In search of partners: linking extracellular proteases to substrates. Nat. Rev. Mol. Cell Biol. 8, 245-257.

2. Sternlicht, M. D. \& Werb, Z. (2001). How matrix metalloproteinases regulate cell behavior. Annu. Rev. Cell Dev. Biol. 17, 463-516.

3. Allan, J. A., Docherty, A. J., Barker, P. J., Huskisson, N. S., Reynolds, J. J. \& Murphy, G. (1995). Binding of gelatinases $\mathrm{A}$ and $\mathrm{B}$ to type-I collagen and other matrix components. Biochem. J. 309, 299-306.

4. Van den Steen, P. E., Van Aelst, I., Hvidberg, V., Piccard, H., Fiten, P., Jacobsen, C. et al. (2006). The hemopexin and $O$-glycosylated domains tune gelatinase B/MMP9 bioavailability via inhibition and binding to cargo receptors. J. Biol. Chem. 281, 18626-18637.

5. Bachmeier, B. E., Iancu, C. M., Jocum, M. \& Nerlich, A. G. (2005). Matrix metalloproteinases in cancer: comparison of known and novel aspects of their inhibition as a therapeutic approach. Exp. Rev. Anticancer Ther. 5, 149-163.

6. Mook, O. R., Frederiks, W. M. \& Van Noorden, J. (2004). The role of gelatinases in colorectal cancer progression and metastasis. Biochim. Biophys. Acta, 1705, 69-89.

7. Strongin, A. Y., Collier, I., Bannikov, G., Marmer, B. L., Grant, G. A. \& Goldberg, G. I. (1995). Mechanism of cell surface activation of $72-\mathrm{kDa}$ type IV collagenase. Isolation of the activated form of the membrane metalloprotease. J. Biol. Chem. 270, 5331-5338.

8. Seiki, M. (1999). Membrane-type matrix metalloproteinases. Acta Pathol., Microbiol. Immunol. Scand. 107, 137-143.

9. Ramos-DeSimone, N., Hahn-Dantona, E., Sipley, J., Nagase, H., French, D. L. \& Quigley, J. P. (1999) Activation of matrix metalloproteinase-9 (MMP9) via a converging plasmin/stromelysin-1 cascade enhances tumor cell invasion. J. Biol. Chem. 274, 13066-13076.

10. Opdenakker, G., Van den Steen, P. E. \& Van Damme, J. (2001). Gelatinase B: a tuner and amplifier of immune functions. Trends Immunol. 22, 571-579.

11. Robinson, S. N., Pisarev, V. M., Chavez, J. M., Singh, R. K. \& Talmadge, J. E. (2003). Use of matrix metalloproteinase MMP9 knockout mice demonstrates that MMP9 activity is not absolutely required for G-CSF or Flt-3 ligand-induced hematopoietic progenitor cell mobilization or engraftment. Stem Cells, 21, 417-427.

12. Asahi, M., Sumii, T., Fini, M. E., Itohara, S. \& Lo, E. H. (2001). Matrix metalloproteinase 2 gene knockout has no effect on acute brain injury after focal ischemia. NeuroReport, 12, 3003-3007.

13. Itoh, T., Ikeda, T., Gomi, H., Nakao, S., Suzuki, T. \& Itohara, S. (1997). Unaltered secretion of betaamyloid precursor protein in gelatinase A (matrix metalloproteinase 2)-deficient mice. J. Biol. Chem. 272, 22389-22392.

14. Leclercq, A., Houard, X., Philippe, M., Ollivier, V., Sebbag, U., Meilhac, O. \& Michel, J. B. (2007).
Involvement of intraplaque hemorrhage in atherothrombosis evolution via neutrophil protease enrichment. J. Leukocyte Biol. 82, 1420-1429.

15. Reichel, C. A., Rehberg, M., Bihari, P., Moser, C. M., Linder, S., Khandaga, A. \& Krombach, F. (2008). Gelatinases mediate neutrophil recruitment in vivo: evidence for stimulus specificity and a critical role in collagen IV remodelling. J. Leukocyte Biol. 83, 864-874.

16. Kühn, K. (1995). Basement membrane (type IV) collagen. Matrix Biol. 14, 439-445.

17. Prockop, D. J. \& Kivirikko, K. I. (1995). Collagens: molecular biology, diseases, and potentials for therapy. Annu. Rev. Biochem. 64, 403-434.

18. Dolz, R., Engel, J. \& Kühn, K. (1988). Folding of collagen IV. Eur. J. Biochem. 178, 357-366.

19. Timpl, R., Wiedemann, H., van Delden, V., Furthmayr, H. \& Kühn, K. (1981). A network model for the organization of type IV collagen molecules in basement membranes. Eur. J. Biochem. 120, 203-211.

20. Timpl, R. (1989). Structure and biological activity of basement membrane proteins. Eur. J. Biochem. 180, 487-502.

21. Paulsson, M. (1992). Basement membrane proteins: structure, assembly, and cellular interactions. Crit. Rev. Biochem. Mol. Biol. 27, 93-127.

22. Kühn, K., Wiedemann, H., Timpl, R., Risteli, J., Dieringer, H., Voss, T. \& Glanville, R. W. (1981). Macromolecular structure of basement membrane collagens. FEBS Lett. 125, 123-128.

23. Kalluri, R. (2003). Basement membranes: structure, assembly and role in tumour angiogenesis. Nat. Rev. Cancer, 3, 422-433.

24. Hamano, Y., Zeisberg, M., Sugimoto, H., Lively, J. C., Maeshima, Y., Yang, C. et al. (2003). Physiological levels of tumstatin, a fragment of collagen IV alpha3 chain, are generated by MMP9 proteolysis and suppress angiogenesis via alphaV $\beta 3$ integrin. Cancer Cell, 3, 589-601.

25. Hamano, Y. \& Kalluri, R. (2005). Tumstatin, the NC1 domain of alpha3 chain of type IV collagen, is an endogenous inhibitor of pathological angiogenesis and suppresses tumor growth. Biochem. Biophys. Res. Commun. 29, 292-298.

26. Kamphaus, G. D., Colorado, P. C., Panka, D. J., Hopfer, H., Ramchandran, R., Torre, A. et al. (2000). Canstatin, a novel matrix-derived inhibitor of angiogenesis and tumor growth. J. Biol. Chem. 275, 1209-1215.

27. Lauer-Fields, J. L., Cudic, M., Wei, S., Mari, F., Fields, G. B. \& Brew, K. (2007). Engineered sarafotoxins as tissue inhibitor of metalloproteinases-like matrix metalloproteinase inhibitors. J. Biol. Chem. 282, 26948-26955.

28. Lauer-Fields, J. L., Whitehead, J. K., Li, S., Hammer, R. P., Brew, K. \& Fields, G. B. (2008). Selective modulation of matrix metalloproteinase 9 (MMP9) functions via exosite inhibition. J. Biol. Chem. 283, 21779-21788.

29. Steffensen, B., Wallon, U. M. \& Overall, C. M. (1995). Extracellular matrix binding properties of recombinant fibronectin type II-like modules of human 72$\mathrm{kDa}$ gelatinase/type IV collagenase. High affinity binding to native type I collagen but not native type IV collagen. J. Biol. Chem. 270, 11555-11566.

30. Tam, E. M., Moore, T. R., Butler, G. S. \& Overall, C. M. (2004). Characterization of the distinct collagen binding, helicase and cleavage mechanisms of matrix metalloproteinase 2 and 14 (gelatinase A and MT1-MMP): the differential roles of the MMP hemopexin $\mathrm{C}$ domains and the MMP2 fibronectin 
type II modules in collagen triple helicase activities. J. Biol. Chem. 279, 43336-43344.

31. Xu, X., Chen, Z., Wang, Y., Yamada, Y. \& Steffensen, B. (2005). Functional basis for the overlap in ligand interactions and substrate specificities of matrix metalloproteinases-9 and -2. Biochem. J. 392, 127-134.

32. Xu, X., Wang, Y., Lauer-Fields, J. L., Fields, G. B. \& Steffensen, B. (2004). Contributions of the MMP2 collagen binding domains to gelatin cleavage. Substrate binding via the collagen binding domain is required for hydrolysis of gelatin but not short peptides. Matrix Biol. 23, 171-181.

33. Xu, X., Chen, Z., Wang, Y., Bonewald, L. \& Steffensen, B. (2007). Inhibition of MMP2 gelatinolysis by targeting exodomain-substrate interactions. Biochem. J. 406, 147-155.

34. Gioia, M., Monaco, S., Fasciglione, G. F., Coletti, A., Modesti, A., Marini, S. \& Coletta, M. (2007). Characterization of the mechanisms by which gelatinase A, neutrophil collagenase, and membranetype metalloproteinase MMP14 recognize collagen I and enzymatically process the two alpha-chains. J. Mol. Biol. 368, 1101-1113.

35. Mackay, A. R., Hartzler, J. L., Pelina, M. D. \& Thorgeirsson, U. P. (1990). Studies on the ability of 65-kDa and 92-kDa tumor cell gelatinases to degrade type IV collagen. J. Biol. Chem. 265, 21929-21934.

36. Monaco, S., Sparano, V., Gioia, M., Sbardella, D., Di Pierro, D., Marini, S. \& Coletta, M. (2006). Enzymatic processing of collagen IV by MMP2 (gelatinase A) affects neutrophil migration and it is modulated by extracatalytic domains. Protein Sci. 15, 2805-2815.

37. Soininen, R., Haka-Risku, T., Prockop, D. J. \& Tryggvason, K. (1987). Complete primary structure of the alpha-1 chain of human basement membrane (type IV) collagen. FEBS Lett. 225, 188-194.

38. Hostikka, S. L. A. \& Tryggvason, K. (1987). Extensive structural differences between genes for the alpha-1 and alpha-2 chains of type IV collagen despite conservation of coding sequences. FEBS Lett. 224, 297-305.

39. Kajimura, D., Takahashi, S., Yoshikawa, K., Hattori, S., Sado, Y., Imamura, Y. \& Hayashi, T. (2004). Nonhelical type IV collagen polypeptides in human placenta. Biochem. Biophys. Res. Commun. 314, 11-16.

40. Briknarova, K., Gehrmann, M., Banyai, L., Tordai, H., Patthy, L. \& Llinas, M. (2001). Gelatin-binding region of human matrix metalloproteinase-2: solution structure, dynamics, and function of the COL-23 twodomain construct. J. Biol. Chem. 276, 27613-27621.

41. Van den Steen, P. E., Dubois, B., Nelisse, I., Rudd, P. M., Dwek, R. A. \& Opdenakker, G. (2002). Biochemistry and molecular biology of gelatinase B or matrix metalloproteinase-9 (MMP9). Crit. Rev. Biochem. Mol. Biol. 37, 375-536.

42. Ardi, V. C., Kupriyanova, T. A., Deryugina, E. I. \& Quigley, J. P. (2007). Human neutrophils uniquely release TIMP-free MMP9 to provide a potent catalytic stimulator of angiogenesis. Proc. Natl Acad. Sci. USA, 104, 20262-20267.

43. Bergers, G., Brekken, R., McMahon, G., Vu, T. H., Itoh, T., Tamaki, K. et al. (2000). Matrix metalloproteinase-9 triggers the angiogenic switch during carcinogenesis. Nat. Cell Biol. 2, 737-744.

44. Itoh, T., Tanioka, M., Yoshida, H., Yoshioka, T., Nishimoto, H. \& Itohara, S. (1998). Reduced angiogenesis and tumor progression in gelatinase A-deficient mice. Cancer Res. 58, 1048-1051.
45. Himelstein, B. P., Canete-Soler, R., Bernhard, E. J., Dilks, D. W. \& Muschel, R. J. (1994). Metalloproteinases in tumor progression: the contribution of MMP9. Invasion Metastasis, 14, 246-258.

46. Ueda, Y., Imai, K., Tsuchiya, H., Fujimoto, N., Nakanishi, I., Katsuda, S. et al. (1996). Matrix metalloproteinase 9 (gelatinase B) is expressed in multinucleated giant cells of human giant cell tumor of bone and is associated with vascular invasion. Am. J. Pathol. 148, 611-622.

47. Ohashi, K., Kawai, R., Hara, M., Okada, Y., Tachibana, S. \& Ogura, Y. (1996). Increased matrix metalloproteinases as possible cause of osteoarticular tissue destruction in long-term haemodyalisis and beta 2-microglobulin amyloidosis. Virchows Arch. 428, $37-46$.

48. Vidovszky, T. J., Cabanela, M. E., Rock, M. G., Berry, D. J., Morrey, B. F. \& Bolander, M. E. (1998). Histologic and biochemical differences between osteolytic and nonosteolytic membranes around femoral components of an uncemented total hip arthroplasty. J. Arthroplasty, 13, 320-330.

49. Opdenakker, G., Nelissen, I. \& van Damme, J. (2003). Functional roles and therapeutic targeting of gelatinase B and chemokines in multiple sclerosis. Lancet Neurol. 2, 747-756.

50. Gutiérrez-Fernández, A., Inada, M., Balbín, M., Fueyo, A., Pitiot, A. S., Astudillo, A. et al. (2007). Increased inflammation delays wound healing in mice deficient in collagenase-2 (MMP8). FASEB J. 21, 2580-2591.

51. Longo, G. M., Xiong, W., Greiner, T. C., Zhao, Y., Fiotti, N. \& Baxter, B. T. (2002). Matrix metalloproteinases 2 and 9 work in concert to produce aortic aneurysms. J. Clin. Invest. 110, 625-632.

52. Itoh, T., Matsuda, H., Tanioka, M., Kuwabara, K., Itohara, S. \& Suzuki, R. (2002). The role of matrix metalloproteinase-2 and matrix metalloproteinase-9 in antibody-induced arthritis. J. Immunol. 169, 2643-2647.

53. Tanjore, H. \& Kalluri, R. (2006). The role of type IV collagen and basement membranes in cancer progression and metastasis. Am. J. Pathol. 168, 715-717.

54. Bányai, L. \& Patthy, L. (1991). Evidence for the involvement of type II domains in collagen binding by $72-\mathrm{kDa}$ type IV procollagenase. FEBS Lett. 282, 23-25.

55. Bradford, M. M. (1976). A rapid and sensitive method for the quantitation of microgram quantities of protein utilizing the principle of protein-dye binding. Anal. Biochem. 72, 248-254.

56. Masure, S., Proost, P., Van Damme, J. \& Opdenakker, G. (1991). Purification and identification of 91-kDa neutrophil gelatinase. Release by the activating peptide interleukin-8. Eur. J. Biochem. 198, 391-398.

57. Laemmlli, U. K. (1970). Cleavage of structural proteins during the assembly of the head of bacteriophage T4. Nature, 227, 680-685.

58. Ventzki, R., Rüggeberg, S., Leicht, S., Franz, T. \& Stegemann, J. (2007). Comparative 2-DE protein analysis in a 3-D geometry gel. BioTechniques, 42, 271-275.

59. Ishihama, Y., Rappsilber, J. \& Mann, M. (2006). SCXStage tip separation using C18-SCX-C18 Stage tip analyzed by LC-MS. J. Proteome Res. 5, 988-999.

60. Knight, C. G., Willenbrock, F. \& Murphy, G. (1992). A novel coumarin-labelled peptide for sensitive continuous assays of the matrix metalloproteinases. FEBS Lett. 296, 263-266. 
61. Wyman, J., Jr (1964). Linked functions and reciprocal effects in hemoglobin: a second look. Adv. Protein Chem. 19, 223-286.

62. Ciaccio, C., Tundo, G.R., Grasso, G., Spoto, G. Marasco, D., Ruvo, M. et al. (2009). Somatostatin: a novel substrate and a modulator of insulin-degrading enzyme activity. J. Mol. Biol. In the press. doi:10.1016/ j.jmb.2008.11.025.
63. Myszka, D. G. \& Morton, T. A. (1998). CLAMP: a biosensor kinetic data analysis program. Trends Biochem. Sci. 23, 149-150.

64. Felkel, C., Schöll, U., Mäder, M., Schwartz, P., Felgenhauer, K., Hardeland, R. et al. (2001). Migration of human granulocytes through reconstituted basement membrane is not dependent on matrix metalloproteinase-9 (MMP9). J. Neuroimmunol. 116, 49-55. 